NBER WORKING PAPER SERIES

\title{
OPTIMAL FISCAL POLICY WITHOUT COMMITMENT: BEYOND LUCAS-STOKEY
}

\author{
Davide Debortoli \\ Ricardo Nunes \\ Pierre Yared \\ Working Paper 24522 \\ http://www.nber.org/papers/w24522 \\ NATIONAL BUREAU OF ECONOMIC RESEARCH \\ 1050 Massachusetts Avenue \\ Cambridge, MA 02138 \\ April 2018
}

We would like to thank Manuel Amador, Facundo Piguillem, Jesse Schreger, and seminar participants at Columbia, Federal Reserve Bank of Boston, University of Toronto, and the ASSA meetings for comments. George Vojta provided excellent research assistance. The views expressed herein are those of the authors and do not necessarily reflect the views of the National Bureau of Economic Research.

NBER working papers are circulated for discussion and comment purposes. They have not been peerreviewed or been subject to the review by the NBER Board of Directors that accompanies official NBER publications.

(C) 2018 by Davide Debortoli, Ricardo Nunes, and Pierre Yared. All rights reserved. Short sections of text, not to exceed two paragraphs, may be quoted without explicit permission provided that full credit, including $\odot$ notice, is given to the source. 
Optimal Fiscal Policy without Commitment: Beyond Lucas-Stokey

Davide Debortoli, Ricardo Nunes, and Pierre Yared

NBER Working Paper No. 24522

April 2018, Revised February 2019

JEL No. E62,H21,H63

\begin{abstract}
$\underline{\text { ABSTRACT }}$
According to the Lucas-Stokey result, a government can structure its debt maturity to guarantee commitment to optimal fiscal policy by future governments. In this paper, we overturn this conclusion, showing that it does not generally hold in the same model and under the same definition of time-consistency as in Lucas-Stokey. Our argument rests on the existence of an overlooked commitment problem that cannot be remedied with debt maturity: a government in the future will not tax on the downward slopping side of the Laffer curve, even if it is ex-ante optimal to do so. In light of this finding, we propose a new framework to characterize time-consistent policy. We consider a Markov Perfect Competitive Equilibrium, where a government reoptimizes sequentially and may deviate from the optimal commitment policy. We find that, in a deterministic economy, any stationary distribution of debt maturity must be flat, with the government owing the same amount at all future dates.
\end{abstract}

Davide Debortoli

Universitat Pompeu Fabra and Barcelona GSE davide.debortoli@upf.edu

Ricardo Nunes

University of Surrey

ricardo.nunes@surrey.ac.uk
Pierre Yared

Columbia University

Graduate School of Business

3022 Broadway, Uris Hall 823

New York, NY 10027

and NBER

pyared@columbia.edu 


\section{Introduction}

In a seminal paper, Lucas and Stokey (1983) consider a closed economy with no capital in which the government finances exogenous spending with taxes and debt. They argue that if the government can issue a sufficiently rich maturity of bonds, then the optimal policy is time-consistent. That is, if given the opportunity to reevaluate policy ex-post, the government would choose the ex-ante optimal policy. This result has led to a large literature that builds on this analysis, such as Alvarez et al. (2004), Persson et al. (2006), and Debortoli et al. (2017), among others.

In this paper, we overturn this conclusion, showing that it does not generally hold in the same model and under the same definition of time-consistency as in Lucas-Stokey. Our argument rests on a simple example in which a commitment problem arises that cannot be remedied with debt maturity. In this example, the government wants to roll over some initial short-term debt. If initial debt is small enough, optimal policy under commitment requires future governments to choose low tax rates on the upward sloping portion of the Laffer curve, and the policy is time-consistent. In contrast, and more interestingly, if initial debt is large enough, optimal policy under commitment requires future governments to choose high tax rates on the downward sloping portion of the Laffer curve. This is optimal ex-ante since the reduction in future consumption decreases shortterm interest rates today, allowing today's government to roll over debt at a lower cost. However, a problem arises since the government tomorrow strictly prefers to repay any rolled over debt with a lower tax rate on the upward sloping portion of the Laffer curve, as this maximizes consumption and welfare ex-post. Therefore, the optimal policy under commitment cannot be sustained under lack of commitment: the government in the future would never choose the preferred future tax rate of the government today, independently of the inherited government debt maturity.

Our argument does not rely on the presence of non-concavities in the government's program and multiplicity of solutions at any date. Our example uses commonly applied isoelastic preferences in which the program is concave and the constraint set is convex at all dates. We show that under these preferences, the Lucas-Stokey procedure for guaranteeing time-consistency need not always work. More specifically, the procedure takes the optimal commitment allocation and then selects a sequence of debt portfolios and Lagrange multipliers (on future governments' budget constraints) to satisfy future governments' first order conditions under this allocation. Assuming future debt portfolios are positive at all maturities, this procedure guarantees time-consistency if the constructed

future Lagrange multipliers are all positive. However, the procedure is invalid if some 
constructed multipliers are negative, since the shadow cost of debt cannot be negative along the equilibrium path. When the constructed multiplier is negative, today's government and the future government disagree as to which tax rate should be chosen to satisfy the future budget constraint, and optimal policy is not time-consistent. From a practical viewpoint, this observation means that implementation of the Lucas-Stokey procedure to guarantee time-consistency may be valid, but it must be checked quantitatively. In some economies, the procedure works, whereas in others - like in our example - it does not. ${ }^{1}$

Given the limitations of the Lucas-Stokey analysis, we propose an alternative approach to studying fiscal policy under lack of commitment. Rather than analyzing whether the optimal commitment policy survives a one-time future reoptimization, as in Lucas-Stokey, we characterize the Markov Perfect Competitive Equilibrium (MPCE). In our setup, the government without commitment chooses taxes and debt at every date, taking into account how current policy affects the price of bonds through expectations of future policy. Moreover, the government may decide not to follow the optimal commitment policy. We characterize the entire set of MPCE's in a deterministic economy, including those with potentially discontinuous policy functions both on and off the equilibrium path. ${ }^{2}$ Since we allow for any unconstrained structure of maturity issuance, the payoff relevant state - the government's portfolio of inherited maturities - is an infinite-dimensional and potentially complicated object. We focus our attention on the stationary maturity distribution that emerges when the inherited portfolio of maturities equals the issued portfolio.

Our main result is that any stationary maturity distribution under lack of commitment must be flat, with the government owing the same amount at all future dates. The fact that a flat maturity distribution is stationary is not surprising. Under a flat maturity distribution, the government lacking commitment can choose a tax rate to repay the debt immediately due without rebalancing its portfolio. The chosen tax rate coincides with the optimum under full commitment, and therefore maximizes government's welfare. What is less obvious is why no other maturity distribution is stationary. The reason is that a government that inherits a non-flat maturity distribution would always take advantage of the situation to front-load or back-load taxes in order to change interest rates. When the government does this, the issued maturity distribution does not coincide with the inherited one, implying that the inherited distribution is not stationary.

For example, suppose that the government inherits more long-term liabilities than

\footnotetext{
${ }^{1}$ Our example suggests that validation should depend intuitively on the extent to which optimal taxes are on the downward sloping part of the Laffer curve. See Trabandt and Uhlig (2011) for quantitative work analyzing the shape of the Laffer curve in advanced economies.

${ }^{2}$ In this regard, our approach is similar in spirit to that of Cao and Werning (2018) in their analysis of Markov equilibria in the hyperbolic consumption model.
} 
short-term ones. Rather than issue the same maturity distribution as the inherited one, the government can change taxes so as to increase short-term interest rates. This relaxes the government budget constraint by decreasing the market value of outstanding long-term liabilities, making the government strictly better off. The opposite is true if the government inherits more short-term liabilities than long-term ones. In this case, a policy that decreases short-term interest rates makes the government strictly better off by increasing the market value of newly issued liabilities.

We apply this simple logic to analyze the behavior of the government inheriting any infinite-dimensional maturity distribution. We show that only if the inherited maturity distribution is flat is the government unable to take advantage of imbalances in debt positions to relax its budget constraint. As such, any stationary maturity distribution must be flat.

Our analysis thus provides a theoretical argument for the use of consols in debt management based on the sequential optimization of fiscal policy by the government. The use of consols has been pursued historically, most notably by the British government during the Industrial Revolution, when consols were the largest component of the British government's debt (see Mokyr, 2011). Moreover, the introduction of consols has been discussed as a potential option in the management of U.S. government debt (e.g. Cochrane, 2015).

\section{Related Literature}

The main contribution of this paper is to highlight the limitations of the Lucas-Stokey analysis, and to offer an alternative approach to the study of optimal fiscal policy under lack of commitment. Our work also contributes to a literature on optimal government debt maturity in the absence of government commitment. We depart from this literature in two ways. First, we consider the optimal maturity without imposing arbitrary constraints on the bonds available to the government. ${ }^{3}$ Second, our model is most applicable to economies where the risk of default and surprise in inflation are not salient, but the government is still not committed to a path of taxes and debt maturity issuance. ${ }^{4}$ In this regard, our paper is related to the quantitative analysis of Debortoli et al. (2017). We differ from this work in two respects. First, we do not arbitrarily confine the set of bonds available to the government, as they do. Second, we consider a deterministic economy and

\footnotetext{
${ }^{3}$ Krusell et al. (2006) and Debortoli and Nunes (2013) consider a similar environment to ours in the absence of commitment, but with only one-period bonds, for example.

${ }^{4}$ Other work considers optimal government debt maturity in the presence of default risk, for example, Aguiar et al. (2017), Arellano and Ramanarayanan (2012), Dovis (2019), Fernandez and Martin (2015), and Niepelt (2014), among others. Bocola and Dovis (2016) additionally consider the presence of liquidity risk. Bigio et al. (2017) consider debt maturity in the presence of transactions costs. Arellano et al. (2013) consider lack of commitment when surprise inflation is possible.
} 
ignore the presence of shocks. ${ }^{5}$ These two departures allow us to achieve exact theoretical characterization of the stationary maturity distribution. Our finding that the maturity distribution is exactly flat is consistent with their quantitative result that the maturity distribution is approximately flat.

Our paper proceeds as follows. In Section 2, we describe the model. In Section 3 , we show that the availability of rich debt maturities does not guarantee the timeconsistency of optimal policy, using the same definition of time-consistency as in LucasStokey. In Section 4, we move beyond Lucas-Stokey and formally define an MPCE. Section 5 establishes that any stationary maturity distribution under lack of commitment is flat. Section 6 concludes, and the Appendix provides all of the proofs and additional results not included in the text.

\section{Model}

\subsection{Environment}

We consider an economy identical to the deterministic case of Lucas-Stokey. There are discrete time periods $t=\{0,1, \ldots, \infty\}$. The resource constraint of the economy is

$$
c_{t}+g=n_{t},
$$

where $c_{t}$ is consumption, $n_{t}$ is labor, and $g>0$ is government spending, which is exogenous and constant over time.

There is a continuum of mass 1 of identical households that derive the following utility:

$$
\sum_{t=0}^{\infty} \beta^{t} u\left(c_{t}, n_{t}\right), \beta \in(0,1)
$$

$u(\cdot)$ is strictly increasing in consumption, strictly decreasing in labor, globally concave, and continuously differentiable. We also assume that $u_{c c}(c, c+g)+u_{c n}(c, c+g)<0$ so that the marginal utility of consumption is decreasing in consumption in general equilibrium. As a benchmark, we define the first best consumption and labor $\left\{c^{f b}, n^{f b}\right\}$ as the values of consumption and labor that maximize $u\left(c_{t}, n_{t}\right)$ subject to the resource constraint (1).

Household wages equal the marginal product of labor (which is 1 unit of consumption),

\footnotetext{
${ }^{5}$ Angeletos (2002), Bhandari et al. (2017), Buera and Nicolini (2004), Faraglia et al. (2010), Guibaud et al. (2013), and Lustig et al. (2008) also consider optimal government debt maturity in the presence of shocks, but they assume full commitment.
} 
and are taxed at a linear tax rate $\tau_{t} . b_{t, k} \gtreqless 0$ represents government debt purchased by a representative household at $t$, which is a promise to repay 1 unit of consumption at $t+k>t . q_{t, k}$ is the bond price at $t$. At every $t$, the household's allocation and portfolio $\left\{c_{t}, n_{t},\left\{b_{t, k}\right\}_{k=1}^{\infty}\right\}$ must satisfy the household's dynamic budget constraint:

$$
c_{t}+\sum_{k=1}^{\infty} q_{t, k}\left(b_{t, k}-b_{t-1, k+1}\right)=\left(1-\tau_{t}\right) n_{t}+b_{t-1,1} .
$$

$B_{t, k} \gtreqless 0$ represents debt issued by the government at $t$ with a promise to repay 1 unit of consumption at $t+k>t$. At every $t$, government policies $\left\{\tau_{t}, g_{t},\left\{B_{t, k}\right\}_{k=1}^{\infty}\right\}$ must satisfy the government's dynamic budget constraint:

$$
g_{t}+B_{t-1,1}=\tau_{t} n_{t}+\sum_{k=1}^{\infty} q_{t, k}\left(B_{t, k}-B_{t-1, k+1}\right){ }^{6}
$$

The economy is closed, which means that the bonds issued by the government equal the bonds purchased by households:

$$
b_{t, k}=B_{t, k} \forall t, k
$$

Initial debt $\left\{B_{-1, k}\right\}_{k=1}^{\infty}=\left\{b_{-1, k}\right\}_{k=1}^{\infty}$ is exogenous. We assume that there exist debt limits to prevent Ponzi schemes:

$$
b_{t, k} \in[\underline{b}, \bar{b}] \forall t, k \text {. }
$$

In our recursive analysis, we will consider economies where these limits are not binding along the equilibrium path. The government is benevolent and shares the same preferences as the households in (2).

\footnotetext{
${ }^{6}$ We follow the same exposition as in Angeletos (2002) in which the government rebalances its debt in every period by buying back all outstanding debt and then issuing fresh debt at all maturities. This is without loss of generality. For example, if the government at $t-k$ issues debt due at date $t$ of size $B_{t-k, k}$ which it then holds to maturity without issuing additional debt, then all future governments at date $t-k+l$ for $l=1, \ldots, k-1$ will choose $B_{t-k+l, k-l}=B_{t-k, k}$, implying that $B_{t-1,1}=B_{t-k, k}$.
} 


\subsection{Primal Approach}

We follow Lucas-Stokey by taking the primal approach to the characterization of competitive equilibria, since this allows us to abstract away from bond prices and taxes. Let

$$
\left\{c_{t}, n_{t}\right\}_{t=0}^{\infty}
$$

represent a sequence of consumption and labor allocations. We can establish necessary and sufficient conditions for (7) to constitute a competitive equilibrium. The household's optimization problem implies the following intratemporal and intertemporal conditions, respectively:

$$
1-\tau_{t}=-\frac{u_{n}\left(c_{t}, n_{t}\right)}{u_{c}\left(c_{t}, n_{t}\right)} \text { and } q_{t, k}=\frac{\beta^{k} u_{c}\left(c_{t+k}, n_{t+k}\right)}{u_{c}\left(c_{t}, n_{t}\right)} .
$$

Substitution of these conditions into the household's dynamic budget constraint implies the following condition:

$$
u_{c}\left(c_{t}, n_{t}\right) c_{t}+u_{n}\left(c_{t}, n_{t}\right) n_{t}+\sum_{k=1}^{\infty} \beta^{k} u_{c}\left(c_{t+k}, n_{t+k}\right) b_{t, k}=\sum_{k=0}^{\infty} \beta^{k} u_{c}\left(c_{t+k}, n_{t+k}\right) b_{t-1, k+1}
$$

Forward substitution into the above equation and taking into account the absence of Ponzi schemes implies the following implementability condition:

$$
\sum_{k=0}^{\infty} \beta^{k}\left(u_{c}\left(c_{t+k}, n_{t+k}\right) c_{t+k}+u_{n}\left(c_{t+k}, n_{t+k}\right) n_{t+k}\right)=\sum_{k=0}^{\infty} \beta^{k} u_{c}\left(c_{t+k}, n_{t+k}\right) b_{t-1, k+1}
$$

By this reasoning, if a sequence in (7) is generated by a competitive equilibrium, then it necessarily satisfies (1) and (10). We prove in the Appendix that the converse is also true, which leads to the below proposition that is useful for the rest of our analysis.

Lemma 1 (competitive equilibrium) A sequence (7) is a competitive equilibrium if and only if it satisfies (1) $\forall t$ and (10) at $t=0$ given $\left\{b_{-1, k}\right\}_{k=1}^{\infty}$.

Note that this result rests on the fact that the satisfaction of (10) at $t=0$ guarantees the satisfaction of (10) for all future dates, since bonds can be freely chosen so as to satisfy (10) at all future dates for any given sequence (7). 


\section{Lucas-Stokey Revisited}

In this section, we apply the Lucas-Stokey definition of time-consistency, and we provide an example that overturns their conclusion that the optimal policy can be made timeconsistent with the appropriate choice of maturities. We first establish that optimal policy under commitment may require future tax rates to be on the downward sloping side of the Laffer curve. We then show that this implies that optimal policy is not time-consistent, despite the availability of rich maturities.

\subsection{Policy under Commitment}

Consider an economy with isoelastic preferences over consumption $c$ and labor $n$, where

$$
u(c, n)=\log c-\eta \frac{n^{\gamma}}{\gamma}
$$

for $\eta>0$ and $\gamma \geq 1$, which corresponds to a utility function analyzed in Werning (2007).

Under these preferences, (1) and (8) imply that the primary surplus, $\tau n-g$, is equal to $c\left(1-\eta(c+g)^{\gamma}\right)$. To facilitate the discussion, define $c^{\text {laffer }}$ as the level of consumption that maximizes the primary surplus:

$$
c^{\text {laffer }}=\arg \max _{c} c\left(1-\eta(c+g)^{\gamma}\right) .
$$

$c^{\text {laffer }}$ is the level of consumption associated with the maximal tax revenue at the peak of the Laffer curve under tax rate $\tau^{l a f f e r}$. We assume that $g<\left(\frac{1}{\eta}\right)^{1 / \gamma}$ to guarantee that $c^{\text {laffer }}>0$. The primary surplus on the right hand side of (12) is strictly concave in $c$ and equals 0 if $c=0$ (100 percent labor income tax) and $-g$ if $c=c^{f b}$ (0 percent labor income tax). More broadly, if $c>c^{\text {laffer }}$, then the tax rate is below the revenue-maximizing tax rate and the economy is on the upward sloping portion (left hand side) of the Laffer curve. If $c<c^{\text {laffer }}$, then the tax rate is above the revenue-maximizing tax rate and the economy is on the downward sloping portion (right hand side) of the Laffer curve.

Using Lemma 1, we can consider the date 0 government's optimal policy under com- 
mitment, where we have substituted in for labor using the resource constraint (1):

$$
\begin{gathered}
\max _{\left\{c_{t}\right\}_{t=0}^{\infty}} \sum_{t=0}^{\infty} \beta^{t}\left(\log c_{t}-\eta \frac{\left(c_{t}+g\right)^{\gamma}}{\gamma}\right) \\
\text { s.t. } \\
\sum_{t=0}^{\infty} \beta^{t}\left(1-\eta\left(c_{t}+g\right)^{\gamma}-\frac{b_{-1, t+1}}{c_{t}}\right)=0 .
\end{gathered}
$$

Equation (14) represents the date 0 implementability condition, which is the present value constraint of the government.

Suppose that $b_{-1,1}>0$ and $b_{-1, k}=0 \forall k \geq 2$. To guarantee the existence of a solution that satisfies $(14)$, let $b_{-1,1} \leq \bar{b}$ for

$$
\bar{b}=\max _{\widetilde{c}}\left\{\frac{\widetilde{c}}{1-\beta}-\eta \widetilde{c}(\widetilde{c}+g)^{\gamma}-\frac{\beta}{1-\beta} \widetilde{c} \eta g^{\gamma}\right\} .
$$

Since initial debt is non-negative, the left hand side of (14) — which can be equivalently written in relaxed form as a weak inequality constraint - is concave, implying that the constraint set is convex. This leads to the following lemma that characterizes the unique optimum under commitment.

Lemma 2 (optimal policy) The unique solution to (13) - (14) satisfies the following conditions:

1. $c_{t}=c_{1} \forall t \geq 1$,

2. $c_{0}$ and $c_{1}<c_{0}$ are the unique solutions to the following system of equations for some $\mu_{0}>0$

$$
\begin{aligned}
& \frac{1}{c_{0}}-\eta\left(c_{0}+g\right)^{\gamma-1}+\mu_{0}\left(\frac{b_{-1,1}}{c_{0}^{2}}-\eta \gamma\left(c_{0}+g\right)^{\gamma-1}\right)=0 \\
& \frac{1}{c_{1}}-\eta\left(c_{1}+g\right)^{\gamma-1}+\mu_{0}\left(-\eta \gamma\left(c_{1}+g\right)^{\gamma-1}\right)=0, \text { and } \\
& 1-\frac{b_{-1,1}}{c_{0}}-\eta\left(c_{0}+g\right)^{\gamma}+\frac{\beta}{1-\beta}\left(1-\eta\left(c_{1}+g\right)^{\gamma}\right)=0 .
\end{aligned}
$$

3. There exists $b_{-1,1}^{*} \in(0, \bar{b})$ such that the solution admits $c_{1}>c^{\text {laffer }}$ if $b_{-1,1}<b_{-1,1}^{*}$ and $c_{1}<c^{\text {laffer }}$ if $b_{-1,1}>b_{-1,1}^{*}$.

The first part of the lemma states that consumption - and therefore the tax rate - is constant from date 1 onward. Since initial debt due from date 1 onward is constant (and 
equal to zero), tax smoothing and interest rate smoothing from date 1 onward is optimal. The second part of the lemma characterizes the solution in terms of first order conditions for a positive Lagrange multiplier $\mu_{0}$ on the implementability constraint (14). These conditions are necessary and sufficient for optimality given the concavity of the problem. Implicit differentiation of (15) and (16), taking into account second order conditions, implies that initial consumption $c_{0}$ exceeds long-run consumption $c_{1}$, which means that the initial tax rate is below the future tax rate. Back-loading tax rates is optimal since the reduction in future consumption relative to present consumption allows the government to roll over its initial short-term debt at a lower interest rate.

The last part of the lemma states that if initial short-term debt $b_{-1,1}$ is sufficiently high, then future consumption $c_{1}$ is below $c^{\text {laffer }}$, implying that the future tax rate $\tau_{1}$ is above the revenue-maximizing tax rate at the peak of the Laffer curve $\tau^{\text {laffer }}$. This result stems from the fact that the government under commitment accommodates increases in initial short-term debt $b_{-1,1}$ with a reduction in future consumption $c_{1}$ and an increase in the future tax rate $\tau_{1}$. Mathematically, higher $b_{-1,1}$ tightens the implementability constraint (14) which increases the Lagrange multiplier $\mu_{0}$ on this constraint. From (16), a higher value of $\mu_{0}$ leads to a lower value of $c_{1}$, and beyond a certain level $b_{-1,1}^{*}, c_{1}$ declines below $c^{\text {laffer }}$ and $\tau_{1}$ rises above $\tau^{\text {laffer }}$. Conceptually, for $c_{1}>c^{\text {laffer }}$ and $\tau_{1}<\tau^{\text {laffer }}$, the reduction in future consumption $c_{1}$ accommodates an increase in initial short-term debt $b_{-1,1}$ by increasing future revenues and decreasing short-term interest rates. Once $c_{1}$ declines beyond $c^{\text {laffer }}$ and $\tau_{1}$ rises above $\tau^{\text {laffer }}$, the increase in initial short-term debt $b_{-1,1}$ is accommodated with lower short-term interest rates only. If $c_{1}<c^{\text {laffer }}$ and $\tau_{1}>\tau^{\text {laffer }}$, the government at date 0 could instead choose a value of $c_{1}>c^{\text {laffer }}$ and $\tau_{1}<\tau^{\text {laffer }}$ yielding the same future revenue to repay its issued debt. However, doing so is suboptimal and would lead to higher short-term interest rates, significantly reducing the resources raised at date 0 by issuing this debt.

A natural question regards what factors drive the value of $b_{-1,1}^{*}$, since a higher $b_{-1,1}^{*}$ implies a higher debt threshold for future taxes to be on the decreasing side of the Laffer curve. We can establish through computational examples that the value of $b_{-1,1}^{*}$ is increasing in $\beta$, decreasing in $\eta$, and increasing in $\gamma$. Intuitively, taxes are more likely to be on the downward sloping side of the Laffer curve from date 1 onward if either the government is impatient and cares little about future tax distortions ( $\beta$ is low) or if instead tax capacity is limited and low interest rates are required to roll over initial debt $(\eta$ is high or $\gamma$ is low). 


\subsection{Time-Consistency of Policy}

We now show that the policy under commitment may not be time-consistent. We follow Lucas-Stokey and consider what happens if at date 1, policy is reevaluated and chosen by a government with full commitment from date 1 onward. As in Lucas-Stokey, we define an optimal policy as time-consistent if the government at date 1 chooses the same allocation as the government at date 0 .

Given an inherited portfolio of maturities, the government at date 1 solves the following problem:

$$
\begin{aligned}
& \max _{\left\{c_{t}, n_{t}\right\}_{t=0}^{\infty}} \sum_{t=1}^{\infty} \beta^{t-1}\left(\log c_{t}-\eta \frac{\left(c_{t}+g\right)^{\gamma}}{\gamma}\right) \\
& \text { s.t. } \\
& \sum_{t=1}^{\infty} \beta^{t-1}\left(1-\eta\left(c_{t}+g\right)^{\gamma}-\frac{b_{0, t}}{c_{t}}\right)=0 .
\end{aligned}
$$

Letting $\mu_{1}$ represent the Lagrange multiplier on (19), first order conditions with respect to $c_{t}$ are:

$$
\frac{1}{c_{t}}-\eta\left(c_{t}+g\right)^{\gamma-1}+\mu_{1}\left(\frac{b_{0, t}}{c_{t}^{2}}-\eta \gamma\left(c_{t}+g\right)^{\gamma-1}\right)=0 \forall t \geq 1
$$

An optimal policy is therefore time-consistent if the solution to (18) - (19) coincides with the solution to $(13)-(14)$.

Proposition 1 (time-consistency of optimal policy) If $b_{-1,1}<b_{-1,1}^{*}$, then the optimal date 0 policy is time-consistent. If $b_{-1,1}>b_{-1,1}^{*}$, then the optimal date 0 policy is not time-consistent.

If $b_{-1,1}<b_{-1,1}^{*}$, then the optimal date 0 policy can be sustained under lack of commitment with the government at date 0 issuing a flat maturity distribution with $b_{0, k}=b_{0,1}$ $\forall k \geq 1$. Under such a flat distribution, the government at date 1 optimally chooses to smooth tax rates into the future. Moreover, given that date 1 tax rates under commitment are on the upward sloping portion of the Laffer curve, the choice of such tax rates is time-consistent. The date 0 and date 1 government agree about the optimal tax rate to repay this debt.

If instead $b_{-1,1}>b_{-1,1}^{*}$, then the optimal date 0 policy cannot be sustained under lack of commitment. If the government at date 0 tried to induce the date 1 government into a smooth policy from date 1 onward by issuing a flat maturity distribution with $b_{0, k}=b_{0,1} \forall k \geq 1$, the date 1 government would never choose a value $c_{1}<c^{\text {laffer }}$ and 
$\tau_{1}>\tau^{\text {laffer }}$ and would instead repay the inherited debt with a value $c_{1}>c^{\text {laffer }}$ and $\tau_{1}<\tau^{\text {laffer }}$. Choosing a lower tax rate on the upward sloping portion of the Laffer curve increases consumption and increases welfare ex-post. Thus, while the date 0 government can commit the date 1 government to a smooth path of revenue and interest rates, it cannot commit the date 1 government to a particular tax rate. As such, the optimal date 0 policy is not time-consistent.

\subsection{Why the Lucas-Stokey Argument Fails}

It is instructive to consider why the original arguments of Lucas-Stokey fail in this example. In developing their argument, Lucas-Stokey consider the optimal allocation under commitment from the perspective of date 0, which satisfies the following first order condition for $t \geq 1$ (the analog of (16) starting from any arbitrary initial maturity distribution):

$$
\frac{1}{c_{t}}-\eta\left(c_{t}+g\right)^{\gamma-1}+\mu_{0}\left(\frac{b_{-1, t+1}}{c_{t}^{2}}-\eta \gamma\left(c_{t}+g\right)^{\gamma-1}\right)=0 \forall t \geq 1
$$

Lucas-Stokey claim that the optimal policy under commitment at date 0 that satisfies (21) could be made time-consistent at date 1 . They argue that this is possible with the appropriate choice of maturities that satisfy the date 1 implementability condition (19) and the date 1 first order condition (20) for some Lagrange multiplier $\mu_{1}$. Their procedure thus combines (20) and (21) to yield:

$$
\mu_{1}\left(\frac{b_{0, t}}{c_{t}^{2}}-\eta \gamma\left(c_{t}+g\right)^{\gamma-1}\right)=\mu_{0}\left(\frac{b_{-1, t+1}}{c_{t}^{2}}-\eta \gamma\left(c_{t}+g\right)^{\gamma-1}\right),
$$

which determines the issued maturity distribution at date 0 as a function of four objects: the inherited maturity distribution, the optimal allocation, $\mu_{0}$, and $\mu_{1}$.

According to Lucas-Stokey logic, given an optimal allocation and value of $\mu_{0}$ from the perspective of date 0 , a value of $\mu_{1}$ and a portfolio of bonds $\left\{b_{0, k}\right\}_{k=1}^{\infty}$ that satisfy (19) and (22) exist, and therefore, the policy is time-consistent. To see why their logic fails, suppose for illustration that the implied values of $\left\{b_{0, k}\right\}_{k=1}^{\infty}$ are all non-negative, so that the constraint set represented by (19) at date 1 is convex. If the implied value of $\mu_{1}$ is positive, then Lucas-Stokey logic holds and the optimal policy is time-consistent. If instead the implied value of $\mu_{1}$ is negative, then Lucas-Stokey logic fails and the optimal policy is not time-consistent. Intuitively, the solution to (18) - (19) under a positive debt portfolio $\left\{b_{0, k}\right\}_{k=1}^{\infty}$ would never admit a negative multiplier - since the shadow cost of inherited debt is positive - which is why the Lucas-Stokey construction fails in this 
case.

Our specific example illustrates a situation in which $\mu_{1}<0$ and the Lucas-Stokey construction fails. (19) and (22) in our example can be written as

$$
\begin{gathered}
b_{0,1}=c_{1}\left(1-\eta\left(c_{1}+g\right)^{\gamma}\right), \text { and } \\
b_{0,1}=\left(1-\frac{\mu_{0}}{\mu_{1}}\right) \eta \gamma c_{1}^{2}\left(c_{1}+g\right)^{\gamma-1},
\end{gathered}
$$

respectively, for $\mu_{0}$ and $c_{1}$ that satisfy $(15)-(17)$. If $b_{-1,1}<b_{-1,1}^{*}$, the solution to (23)-(24) admits $\mu_{1}>0$, and the optimal policy is time-consistent. If instead $b_{-1,1}>b_{-1,1}^{*}$, the solution to $(23)-(24)$ admits $\mu_{1}<0$, and the optimal policy is not time-consistent.

There are two important points to note regarding this example. First, our example does not rely on the presence of non-concavities in the government's program and multiplicity of solutions at any date. Our isoelastic preferences imply that the government's welfare is concave and the constraint set is convex, which guarantees that the solution to the government's problem at dates 0 and 1 is unique. We conjecture that considering cases with multiplicity (for instance examples with negative debt positions, which make the implementability condition no longer a convex constraint) could make it even more challenging for today's government to induce commitment by future governments.

Second, our example does not rely on the presence of an infinite horizon, which we only choose here to be consistent with Lucas-Stokey. A T-period version of this example would yield the same conclusion, namely that in some cases, the optimal policy under commitment does not coincide with that under lack of commitment. In the Appendix, we evaluate such a finite horizon economy. We show that the same conclusions hold, and we explicitly characterize policy under lack of commitment using backward induction in the cases where the optimal policy is not time-consistent.

\section{Markov Perfect Competitive Equilibrium}

Given the limitations of the Lucas-Stokey analysis, we propose an alternative approach to studying fiscal policy under lack of commitment. Rather than analyzing whether the

optimal commitment policy survives a one-time future reoptimization, we characterize the MPCE in which the government without commitment chooses taxes and debt at every date, taking into account how current policy affects the price of bonds through expectations of future policy. Such a government without commitment may not choose the optimal commitment policy. In this section, we formally define our equilibrium, and 
then, using the primal approach, we provide a recursive representation of the equilibrium.

\subsection{Equilibrium Definition}

Formally, let $\mathbf{B}_{t} \equiv\left\{B_{t, k}\right\}_{k=1}^{\infty}$ and $\mathbf{q}_{t} \equiv\left\{q_{t, k}\right\}_{k=1}^{\infty}$. In every period $t$, the government chooses a policy $\left\{\tau_{t}, \mathbf{B}_{t}\right\}$ given $\mathbf{B}_{t-1}$. Households then choose an allocation and portfolio $\left\{c_{t}, n_{t},\left\{b_{t, k}\right\}_{k=1}^{\infty}\right\}$. An MPCE consists of: a government strategy $\rho\left(\mathbf{B}_{t-1}\right)$ which is a function of $\mathbf{B}_{t-1}$; a household allocation and portfolio strategy $\omega\left(\mathbf{B}_{t-1}, \rho_{t}, \mathbf{q}_{t}\right)$ which is a function of $\mathbf{B}_{t-1}$, the government policy $\rho_{t}=\rho\left(\mathbf{B}_{t-1}\right)$, and bond prices $\mathbf{q}_{t}$; and a set of bond pricing functions $\left\{\varphi^{k}\left(\mathbf{B}_{t-1}, \rho_{t}\right)\right\}_{k=1}^{\infty}$ with $q_{t, k}=\varphi^{k}\left(\mathbf{B}_{t-1}, \rho_{t}\right) \forall k \geq 1$ which depend on $\mathbf{B}_{t-1}$ and the government policy $\rho_{t}=\rho\left(\mathbf{B}_{t-1}\right)$. In an MPCE, these objects must satisfy the following conditions $\forall t$ :

1. The government strategy $\rho(\cdot)$ maximizes (2) given $\omega(\cdot), \varphi^{k}(\cdot) \forall k \geq 1$, and the government budget constraint (4);

2. The household allocation and portfolio strategy $\omega(\cdot)$ maximizes (2) given $\rho(\cdot), \varphi^{k}(\cdot)$ $\forall k \geq 1$, and the household budget constraint (3), and

3. The set of bond pricing functions $\varphi^{k}(\cdot) \forall k \geq 1$ satisfy (5) given $\rho(\cdot)$ and $\omega(\cdot)$.

\subsection{Recursive Representation}

Given our definition, an MPCE is characterized by an equilibrium consumption and labor sequence (7) and an equilibrium debt sequence $\left\{\left\{b_{t, k}\right\}_{k=1}^{\infty}\right\}_{t=0}^{\infty}$, where each element at date $t$ depends on history only through $\mathbf{B}_{t-1}$, the payoff relevant variables. Given this observation, in an MPCE, one can define a function $h^{k}(\cdot)$

$$
h^{k}\left(\mathbf{B}_{t}\right)=\beta^{k} u_{c}\left(c_{t+k}, n_{t+k}\right) \mid \mathbf{B}_{t}
$$

for $k \geq 1$, which equals the discounted marginal utility of consumption at $t+k$ given $\mathbf{B}_{t}$ at $t$. This function is useful since, in choosing $\mathbf{B}_{t}$ at date $t$, the government must take into account how it affects future expectations of policy, which in turn affect current bond prices through expected future marginal utility of consumption.

Note that choosing $\left\{\tau_{t}, \mathbf{B}_{t}\right\}$ at date $t$ from the perspective of the government is equivalent to choosing $\left\{c_{t}, n_{t}, \mathbf{B}_{t}\right\}$ where one can write, with some abuse of notation, $\mathbf{B}_{t}=\left\{b_{t, k}\right\}_{k=1}^{\infty}$, and this follows from the primal approach delineated in Section 2.2. Removing the time subscript and defining $\mathbf{B} \equiv \mathbf{B}_{t-1}=\left\{b_{k}\right\}_{k=1}^{\infty}$ as the inherited portfolio of 
bonds, we can write the government's problem recursively as

$$
\begin{gathered}
V(\mathbf{B})=\max _{c, n, \mathbf{B}^{\prime}} u(c, n)+\beta V\left(\mathbf{B}^{\prime}\right) \\
\text { s.t. } \\
c+g=n, \text { and } \\
u_{c}(c, n) c+u_{n}(c, n) n-u_{c}(c, n) b_{1}+\sum_{k=1}^{\infty} h^{k}\left(\mathbf{B}^{\prime}\right)\left(b_{k}^{\prime}-b_{k+1}\right)=0,
\end{gathered}
$$

where (28) is a recursive representation of (9). Let $f(\mathbf{B})$ correspond to the solution to (26) - (28) given $V(\cdot)$ and $h^{k}(\cdot) \forall k \geq 1$. It therefore follows that the function $f(\cdot)$ necessarily implies functions $h^{k}(\cdot) \forall k \geq 1$ which satisfy (25). An MPCE is therefore composed of functions $V(\cdot), f(\cdot)$, and $h^{k}(\cdot) \forall k \geq 1$ that are consistent with one another and satisfy $(25)-(28)$.

\section{$5 \quad$ Stationary Distribution of Debt Maturity}

We focus on characterizing an economy in which the debt maturity distribution is stationary with $b_{t+1, k}=b_{t, k}, \forall t, k$, so that government debt maturity is time-invariant. Given the Markovian structure of the solution to the MPCE defined by (26) - (28), such a stationary maturity distribution is associated with tax rates, consumption, and interest rates that are constant over time. In this section, we show that any stationary maturity distribution must be flat, with the government owing the same amount of resources to the private sector at all future dates. To establish this result, we first impose a useful assumption in Section 5.1. In Section 5.2, we use this assumption show that a flat maturity distribution is stationary. Finally, in Section 5.3, we show that no other maturity distribution can be stationary.

\subsection{Preliminaries}

Before proceeding with our analysis, we impose a useful assumption. Using our recursive notation introduced in Section 4, define $W\left(\left\{b_{k}\right\}_{k=1}^{\infty}\right)$ as the welfare of the government 
under full commitment given an initial starting debt position $\left\{b_{k}\right\}_{k=1}^{\infty}$ :

$$
\begin{gathered}
W\left(\left\{b_{k}\right\}_{k=1}^{\infty}\right)=\max _{\left\{c_{k}, n_{k}\right\}_{k=0}^{\infty}} \sum_{k=0}^{\infty} \beta^{k} u\left(c_{k}, n_{k}\right) \\
\text { s.t. } \\
c_{k}+g=n_{k} \text {, and } \\
\sum_{k=0}^{\infty} \beta^{k}\left(u_{c}\left(c_{k}, n_{k}\right) c_{k}+u_{n}\left(c_{k}, n_{k}\right) n_{k}\right)=\sum_{k=0}^{\infty} \beta^{k} u_{c}\left(c_{k}, n_{k}\right) b_{k+1} .
\end{gathered}
$$

Given Lemma 1, the program in (29) - (31) corresponds to that of a government under full commitment with $b_{-1, k}=b_{k+1}$.

Assumption 1. Consider the solution to (29)-(31) with $b_{k+1}=b \forall k \geq 0 . \forall b \in[\underline{b}, \bar{b}]$, if the solution exists, then the solution is unique and admits $\left\{c_{k}, n_{k}\right\}=\left\{c^{*}(b), n^{*}(b)\right\}$ $\forall k \geq 0$, where

$$
\begin{gathered}
u_{c}\left(c^{*}(b), n^{*}(b)\right) c^{*}(b)+u_{n}\left(c^{*}(b), n^{*}(b)\right) n^{*}(b)=u_{c}\left(c^{*}(b), n^{*}(b)\right) b, \\
\text { and } c^{*}(b)+g=n^{*}(b) .
\end{gathered}
$$

This assumption states that if a government under full commitment is faced with a flat maturity distribution, then there is a unique optimum in which the government chooses a constant allocation of consumption and labor in the future. ${ }^{7}$ This assumption is intuitive. Under a flat maturity distribution, every time period in the program in (29) - (31) is identical in the objective function and in the constraint set, which suggests that the optimal solution is a time-invariant allocation. A sufficient condition for Assumption 1 is that the function $u_{c}(c, c+g)(c-b)+u_{n}(c, c+g)(c+g)$ is concave in $c$ for all $b$, which is the case, for example, if the utility function satisfies (11) as in our example in Section 3 and if $\underline{b}=0$ so that debt is non-negative.

\subsection{Flat Maturity Distribution is Stationary}

We begin by establishing that if the maturity distribution is flat, then it is stationary.

Lemma 3 Suppose that $\mathbf{B}$ satisfies $b_{k}=b \forall k$ for some $b \in[\underline{b}, \bar{b}]$. Then,

1. In all solutions to $(26)-(28), c=c^{*}(b)$ and $n=n^{*}(b)$, and

\footnotetext{
${ }^{7}$ Assumption 1 requires that the solution exists. If the upper bound on individual maturities $\bar{b}$ exceeds the highest primary surplus that can be raised at the peak of the Laffer curve, then there is no solution under a flat maturity for some high values of debt.
} 
2. There exists a solution to (26) - (28) that admits $b_{k}^{\prime}=b \forall k$.

The first part of the lemma states that in any MPCE, if the government inherits a flat maturity distribution with $b_{k}=b \forall k$, then the unique optimal response of the government is to choose consumption and labor that coincide with the commitment optimum. The second part of the lemma implies that one optimal-but not necessarily uniquely optimal-strategy for the government is to choose $b_{k}^{\prime}=b \forall k$ so that debt is not rebalanced and the maturity distribution continues to be flat in the future. As such, there exists a stationary MPCE with a flat maturity distribution. Importantly, this lemma implies that in any MPCE for which $\mathbf{B}$ is a flat maturity distribution, it is necessary that

$$
V(\mathbf{B})=W(\mathbf{B})
$$

so that there is no welfare loss for the present government due to lack of commitment by future governments.

The logic behind this lemma is that a government inheriting a flat maturity distribution with $b_{k}=b \forall k$ can always decide to not rebalance its debt portfolio and to choose the tax rate associated with $\left\{c^{*}(b), n^{*}(b)\right\}$. Forward induction on this observation combined with Assumption 1 means that the government is able to achieve the commitment optimum with this strategy while inducing allocation $\left\{c^{*}(b), n^{*}(b)\right\}$ in all future periods. Note that the government can induce the commitment allocation in the future in any MPCE, including those where the government's continuation strategy off the equilibrium path given off equilibrium maturities does not coincide with the commitment solution.

\subsection{No Other Maturity Distribution is Stationary}

We now turn to the possibility that another maturity distribution is stationary. We show in this section that this is not possible by contradiction using an induction argument. The first step of the induction argument establishes that if a non-flat maturity distribution were stationary, then the debt immediately due, $b_{1}$, would be necessarily equal to the primary surplus. The second step of the induction argument establishes that if a non-flat maturity distribution were stationary with $b_{k}$ equal to the primary surplus for all $k \leq m$, then $b_{m+1}$ would necessarily be equal to the primary surplus. It follows then by induction that $b_{k}$ equals the primary surplus for all maturities $k$ and that the maturity distribution is flat, leading to a contradiction.

To pursue this induction argument, we establish a preliminary result that allows us to construct perturbations as part of the induction argument. To interpret this lemma, 
observe that since consumption is constant over time under a stationary maturity distribution, the price of a bond maturing in $k$ periods is $\beta^{k}$.

Lemma 4 Suppose that given B, there exists a solution to (26) - (28) with a stationary maturity distribution $b_{k}^{\prime}=b_{k} \forall k$ and $b_{l}^{\prime} \neq b_{m}^{\prime}$ for some $l, m$. Then there exists another solution to (26) - (28) with $b_{k}^{\prime}=\widehat{b} \forall k$ where

$$
\widehat{b}=\sum_{k=1}^{\infty} \beta^{k-1}(1-\beta) b_{k}
$$

This lemma states that under any MPCE with a stationary maturity distribution that is not flat, the government can choose the same tax rate but issue a flat maturity distribution with the same market value and achieve the same welfare. The proof of this lemma is facilitated by Lemma 3, which characterizes the continuation equilibrium following this choice of a flat maturity. Since current and future taxes and consumption remain unchanged from the issuance of a flat maturity, bond prices and welfare are also unchanged.

Lemma 4 implies that if there exists a stationary maturity distribution that is not flat, then the corresponding welfare is equal to that achieved under a flat maturity distribution with the same market value. Moreover, from (34), welfare under this MPCE equals that under commitment associated with a flat maturity distribution with the same market value:

$$
V(\mathbf{B})=\left.W\left(\left\{b_{k}\right\}_{k=1}^{\infty}\right)\right|_{b_{k}=\widehat{b} \forall k}=\frac{u(c(\widehat{b}), n(\widehat{b}))}{1-\beta} .
$$

Lemma 4 is useful since it characterizes welfare under a stationary maturity distribution that is not flat. Moreover, it allows us to consider off-equilibrium welfare following a deviation in maturity issuance strategy by the government, which is useful for establishing the first step of our induction argument in the next lemma.

Lemma 5 Suppose that given B, there exists a solution to (26) - (28) with a stationary maturity distribution $b_{k}^{\prime}=b_{k} \forall k$ and for which $\{c, n\} \neq\left\{c^{f b}, n^{f b}\right\}$. Then, B must satisfy $b_{1}=\widehat{b}$ for $\widehat{b}$ defined in (35).

This lemma states that in any stationary maturity distribution in which the tax rate is not zero (so that consumption and labor do not equal the first best), short-term debt $b_{1}$ equals the annuitized value of total debt $\widehat{b}$. Therefore, the primary surplus equals the short-term debt $b_{1}$ and net debt issuance is zero. 
The proof rests on showing that if the primary surplus is in excess of, or below, this short-term debt $b_{1}$, then the government can pursue a deviation from a smooth consumption path to boost welfare. For example, if the primary surplus is in excess of what the government immediately owes, then pursuit of a smooth consumption path would require the government to buy back some of its long-term debt. Rather than following a stationary debt issuance strategy, the government can back-load consumption to increase short-term interest rates and reduce the value of the long-term debt which it buys back. Since the deviation is beneficial, the maintenance of a stationary debt maturity distribution is not optimal if the primary surplus exceeds $b_{1}$.

If instead the primary surplus is below what the government immediately owes, then pursuit of a smooth consumption path would require the government to issue fresh debt in order to repay current short-term debt. Rather than following a stationary debt issuance strategy, the government can front-load consumption to decrease short-term interest rates and increase the value of newly issued debt. Since the deviation is beneficial, the maintenance of a stationary debt maturity distribution is not optimal if the primary surplus is below $b_{1}$.

Note that in constructing these deviations, we utilize Lemmas 3 and 4 which allow us to characterize the change in welfare if the government issues a flat government debt maturity today as part of its deviation. As such, we can explicitly show that these deviations increase welfare by relaxing the government's budget constraint.

Note that the reason why our argument does not hold under a stationary distribution of debt maturities with zero taxes is that in this case, it is not possible to relax the government budget constraint further.

We now use analogous arguments to establish the second step of the induction argument.

Lemma 6 Suppose that given $\mathbf{B}$, there exists a solution to (26) - (28) with a stationary maturity distribution $b_{k}^{\prime}=b_{k} \forall k$ and for which $\{c, n\} \neq\left\{c^{f b}, n^{f b}\right\}$. If $b_{l}=\widehat{b} \forall l \leq m$, then B must satisfy $b_{m+1}=\widehat{b}$ for $\widehat{b}$ defined in (35).

This lemma considers the stationary maturity distribution when all bond maturities below $m$ equal the primary surplus of the government (the annuitized value of government debt). When this is the case, then the bond of maturity $m+1$ must also equal the primary surplus of the government.

The argument, which relies on a proof by contradiction, starts from the fact that under a stationary maturity distribution, government's welfare satisfies (36), and thus equals welfare under commitment with a flat maturity distribution with the same market 
value. Now if the amount owed at date $m+1$ does not also equal the primary surplus, then there exists a feasible deviation from a stationary debt issuance strategy that can increase welfare above (36), leading to a contradiction.

More specifically, if $b_{l}=\widehat{b} \forall l \leq m$ but $b_{m+1} \neq \widehat{b}$, a feasible strategy for the government today is to continue to choose the same consumption and labor allocation today $\{c(\widehat{b}), n(\widehat{b})\}$ but to deviate by not retrading the inherited maturities (i.e., letting the bonds mature to next period). Such a deviation is feasible whatever the expectations of future policy and their impact on current bond prices since the government is not rebalancing its portfolio.

Without needing to specify the exact form of the continuation equilibrium, we can show that this deviation must necessarily increase welfare. The argument rests on putting a lower bound on the welfare of future governments following the deviation based on the feasible policies at their disposal. More specifically, note that after the initial deviation, future governments also have the opportunity to pursue the same strategy of choosing consumption and labor equal to $\{c(\widehat{b}), n(\widehat{b})\}$ and not rebalancing the portfolio of maturities. This is true up until some future date $m$ periods in the future. Based on this logic, the welfare of the government today from pursuing the deviation must weakly exceed

$$
\sum_{l=0}^{m-1} \beta^{l} u(c(\widehat{b}), n(\widehat{b}))+\beta^{m} V(\widehat{\mathbf{B}}(m))
$$

where $\widehat{\mathbf{B}}(m)$ satisfies $\widehat{b}(m)_{k}=b_{k+m} \forall k \geq 1$. Thus, for the initial deviation to be weakly dominated, this requires (37) to be weakly exceeded by (36), so that

$$
V(\widehat{\mathbf{B}}(m)) \leq \frac{u(c(\widehat{b}), n(\widehat{b}))}{1-\beta}
$$

However, since $b_{m+1} \neq \widehat{b}$, the arguments of Lemma 5 imply that (38) cannot hold, leading to a contradiction. Intuitively, $m$ periods into the future after following a strategy of no rebalancing, the primary surplus is above or below the debt immediately due. At this point in the future, pursuing a strategy that back-loads or front-loads consumption strictly increases welfare relative to a smooth consumption policy with a stationary debt issuance strategy. Therefore, the immediate deviation prior to reaching this $m$ 'th period is beneficial, and the maintenance of a stationary debt maturity distribution is not optimal.

Proposition 2 (flat maturity) Suppose that conditional on $\mathbf{B}$, there exists a solution to $(26)-(28)$ with a stationary maturity distribution $b_{k}^{\prime}=b_{k} \forall k$ and for which $\{c, n\} \neq$ 
$\left\{c^{f b}, n^{f b}\right\}$. Then it is necessary that $b_{k}=\widehat{b} \forall k$ so that the maturity distribution is flat.

This proposition represents the main result of the paper. It states that if the maturity distribution is stationary and if the equilibrium does not entail first best consumption and labor, then the maturity distribution is flat. The reasoning for the proposition follows from induction arguments which appeal to Lemmas 5 and 6 . Intuitively, if maturity distribution is not flat, then there are opportunities for the government take advantage of these imbalances to decrease the market value of its inherited portfolio or increase the market value of its newly-issued portfolio. Note that this result holds in any MPCE and does not appeal to any assumptions regarding the behavior of future governments.

Our result relies on the stationary maturity distribution not being associated with first best consumption and labor. Under such a stationary distribution, taxes would be zero, the market value of debt would be sufficiently negative to finance the stream of government spending forever, and the marginal benefit of resources for the government would be zero. For this reason, the stationary maturity distribution is not determined in this circumstance. We can trivially rule out this case if there are exogenous bounds on government debt which prevent such asset accumulation for the government.

Corollary 1 Suppose that $\underline{b}>-g$. Then if conditional on $\mathbf{B}$, there exists a solution to (26) - (28) with a stationary maturity distribution $b_{k}^{\prime}=b_{k} \forall k$, it is necessary that $b_{k}=\widehat{b}$ $\forall k$ so that the maturity distribution is flat.

Finally, returning to Lemma 3, note that Proposition 2 also implies that starting from a flat maturity distribution, the unique continuation equilibrium requires the issuance of a flat maturity distribution. Therefore, in any MPCE, a flat government debt maturity is an absorbing state, and all flat maturity distributions are stationary.

Corollary 2 Suppose that B satisfies $b_{k}=b \forall k$ for some $b$ and that $\{c, n\} \neq\left\{c^{f b}, n^{f b}\right\}$. Then, in all solutions to $(26)-(28) b_{k}^{\prime}=b \forall k$.

Starting from a flat maturity distribution, the current government would like to guarantee a constant level of consumption and labor going forward. Choosing a maturity distribution that is not flat cannot guarantee such a continuation equilibrium, since future governments will deviate from a smooth policy in order to relax the government budget constraint. For this reason, the government chooses a flat maturity distribution, and a flat maturity distribution is an absorbing state.

A natural question concerns whether an MPCE can converge to a stationary distribution over time. A complete analysis of MPCE's in an infinite horizon economy with 
an infinite choice of debt maturities is analytically infeasible in the cases where the commitment and no-commitment solutions do not coincide; this is because Lucas-Stokey techniques do not apply. In the Appendix, we analyze transitions in a $T$-period economy and we present examples where the economy transitions to a flat maturity distribution in finite time. ${ }^{8}$

\section{Concluding Remarks}

An important literature on optimal fiscal policy without commitment has built on the Lucas-Stokey conclusion that a government can structure its debt maturity to guarantee commitment by future governments. In this paper, we overturn this result, using the same model and the same definition of time-consistency as Lucas-Stokey under standard assumptions on preferences.

Motivated by this finding, we propose an alternative approach to studying fiscal policy under lack of commitment. Rather than analyzing whether the optimal commitment policy survives a one-time future reoptimization, as previous work has done, we characterize the equilibrium when the government reoptimizes sequentially and may deviate from the optimal commitment policy. We consider an MPCE in which the government chooses policy as a function of the infinite-dimensional portfolio of government bonds that it inherits in every period. Our analysis applies to the entire set of MPCE's, including those with potentially discontinuous policy functions both on and off the equilibrium path. We find that any stationary distribution of debt maturity must be flat, with the government owing the same amount at all future dates. Our analysis thus provides a theoretical argument for the use of consols in debt management based on the sequential optimization of fiscal policy by the government.

In our framework, we have considered a situation in which a government's objective in its debt issuance strategy is to minimize its financing costs. In practice, government debt management offices also pursue other objectives, such as supporting financial stability. For example, this can be achieved either by providing liquidity to segments of the market that lack it or through the bond auction process, which itself may serve a purpose of aggregating financial market information. How these factors matter for the optimal maturity management of government debt is an interesting question for future research.

\footnotetext{
${ }^{8}$ These results are consistent with the quantitative analysis of Debortoli et al. (2017) who consider a stochastic infinite horizon with limited debt maturities, and who find that the maturity distribution transitions to an approximately flat one.
} 


\section{References}

Aguiar, M., M. Amador, H. Hopenhayn, and I. Werning (2017). Take the Short Route: Equilibrium Default and Debt Maturity. Working Paper.

Alvarez, F., P. J. Kehoe, and P. A. Neumeyer (2004). The Time Consistency of Optimal Monetary and Fiscal Policies. Econometrica 72(2), 541-567.

Angeletos, G.-M. (2002). Fiscal Policy with Noncontingent Debt and the Optimal Maturity Structure. The Quarterly Journal of Economics 117(3), 1105-1131.

Arellano, C., Y. Bai, P. Kehoe, and A. Ramanarayanan (2013). Credibility and the Maturity of Government Debt. Federal Reserve Bank of Minneapolis, Manuscript.

Arellano, C. and A. Ramanarayanan (2012). Default and the Maturity Structure in Sovereign Bonds. Journal of Political Economy 120(2), 187-232.

Bhandari, A., D. Evans, M. Golosov, and T. J. Sargent (2017). Fiscal Policy and Debt Management with Incomplete Markets. The Quarterly Journal of Economics 132(2), 617-663.

Bigio, S., G. Nuno, and J. Passadore (2017). A Framework for Debt-Maturity Management. Manuscript.

Bocola, L. and A. Dovis (2016). Self-Fulfilling Debt Crises: A Quantitative Analysis. Working Paper.

Buera, F. and J. P. Nicolini (2004). Optimal Maturity of Government Debt without State Contingent Bonds. Journal of Monetary Economics 51(3), 531-554.

Cao, D. and I. Werning (2018). Saving and Dissaving with Hyperbolic Discounting. Econometrica 86(3), 805-857.

Cochrane, J. H. (2015). A New Structure for US Federal Debt. In D. Wessel (Ed.), The 13 Trillion Question: Managing the U.S. Government's Debt, pp. 91-146. Brookings Institution Press.

Debortoli, D. and R. Nunes (2013). Lack of Commitment and the Level of Debt. Journal of the European Economic Association 11(5), 1053-1078.

Debortoli, D., R. Nunes, and P. Yared (2017). Optimal Time-Consistent Government Debt Maturity. The Quarterly Journal of Economics 132(1), 55-102. 
Dovis, A. (2019). Efficient Sovereign Default. The Review of Economic Studies 86(1), $282-312$.

Faraglia, E., A. Marcet, and A. Scott (2010). In Search of a Theory of Debt Management. Journal of Monetary Economics 57(7), 821-836.

Fernandez, R. and A. Martin (2015). The Long and the Short of It: Sovereign Debt Crises and Debt Maturity. Universitat Pompeu Fabra, Working Paper.

Guibaud, S., Y. Nosbusch, and D. Vayanos (2013). Bond Market Clienteles, the Yield Curve, and the Optimal Maturity Structure of Government Debt. Review of Financial Studies 26(8), 1914-1961.

Krusell, P., F. Martin, and J.-V. Ríos-Rull (2006). Time-Consistent Debt. Manuscript.

Lucas, R. E. and N. L. Stokey (1983). Optimal Fiscal and Monetary Policy in an Economy without Capital. Journal of Monetary Economics 12(1), 55-93.

Lustig, H., C. Sleet, and S. Yeltekin (2008). Fiscal Hedging with Nominal Assets. Journal of Monetary Economics 55(4), 710-727.

Mokyr, J. (2011). The Enlightened Economy: Britain and the Industrial Revolution, 1700-1850. Penguin UK.

Niepelt, D. (2014). Debt Maturity without Commitment. Journal of Monetary Economics 68(Supplement), S37-S54.

Persson, M., T. Persson, and L. E. O. Svensson (2006). Time Consistency of Fiscal and Monetary Policy: A Solution. Econometrica $74(1), 193-212$.

Trabandt, M. and H. Uhlig (2011). The Laffer Curve Revisited. Journal of Monetary Economics 58(4), 305-327.

Werning, I. (2007). Optimal Fiscal Policy with Redistribution. The Quarterly Journal of Economics 122(3), 925-967. 


\section{APPENDIX}

\section{Appendix A. Proofs of Section 2}

\section{Proof of Lemma 1}

The necessity of these conditions is proved in the text. To prove sufficiency, let the government choose the associated level of debt $\left\{\left\{b_{t, k}\right\}_{k=1}^{\infty}\right\}_{t=0}^{\infty}$ which satisfies (9) and a tax sequence $\left\{\tau_{t}\right\}_{t=0}^{\infty}$ which satisfies (8). Let bond prices satisfy (8). (9) given (1) implies that (3) and (4) are satisfied. Therefore household optimality holds and all dynamic budget constraints are satisfied along with the market clearing, so the equilibrium is competitive.

\section{Appendix B. Proofs of Section 3}

\section{Proof of Lemma 2}

We prove this lemma in four steps.

Step 1. We first establish that the problem is concave and the solution unique. Consider the relaxed problem in which (14) is replaced with

$$
1-\frac{b_{-1,1}}{c_{0}}-\eta\left(c_{0}+g\right)^{\gamma}+\sum_{t=1}^{\infty} \beta^{t}\left(1-\eta\left(c_{t}+g\right)^{\gamma}\right) \geq 0
$$

We can establish that $(B .1)$ holds as an equality in the relaxed problem, implying that the relaxed and constrained problems are equivalent. If instead (B.1) held as an inequality in the relaxed problem, the solution to the relaxed problem would admit $c_{t}=c^{f b} \forall t$. Given (11), $c^{f b}$ satisfies $\eta c^{f b}\left(c^{f b}+g\right)^{\gamma-1}=1$, and substitution of $c_{t}=c^{f b}$ into (B.1) yields

$$
\frac{1}{c^{f b}}\left(-b_{-1,1}-\frac{1}{1-\beta} g\right) \geq 0
$$

which is a contradiction since $b_{-1,1}>0$. Therefore, (B.1) holds as an equality in the solution to the relaxed problem and the solutions to the relaxed and constrained problems coincide. Since the left hand side of $(B .1)$ is strictly concave in $c_{t}$ given that $b_{-1,1}>0$ and since the objective (13) is strictly concave, it follows that the solution is unique.

Step 2. We now establish the first two parts of the lemma. Letting $\mu_{0}>0$ correspond 
to the Lagrange multiplier on $(B .1)$, the first order condition for $c_{0}$ is $(15)$. The first order condition for $c_{t}$ for all $t \geq 1$ is

$$
\frac{1}{c_{t}}-\eta\left(c_{t}+g\right)^{\gamma-1}+\mu_{0}\left(-\eta \gamma\left(c_{t}+g\right)^{\gamma-1}\right)=0
$$

Since the left hand side of $(B .2)$ is strictly decreasing in $c_{t}$, it follows that the solution to (B.2) is unique with $c_{t}=c_{1} \forall t \geq 1$, where (16) defines $c_{1}$. It follows from the fact that the program is strictly concave and constraint set convex that satisfaction of (15) - (17) is necessary and sufficient for optimality for a given $\mu_{0}>0$. We are left to verify that $c_{0}>c_{1}$. Note that the left hand side of (15) is strictly increasing in $b_{-1,1}$ and strictly decreasing in $c_{0}$ for a given $\mu_{0}>0$. Therefore, $c_{0}$ is strictly increasing in $b_{-1,1}$ for a given $\mu_{0}>0$, where $c_{0}=c_{1}$ if $b_{-1,1}=0$. It follows then that since $b_{-1,1}>0, c_{0}>c_{1}$.

Step 3. We now establish the last part of the lemma. We first show that the solution to the system in $(15)-(17)$ admits $c_{1}$ which is strictly decreasing in $b_{-1,1}$. Let $F^{0}\left(c_{0}, \mu_{0}, b_{-1,1}\right)$ correspond to the function on the left hand side of $(15)$, let $F^{1}\left(c_{1}, \mu_{0}\right)$ correspond to the function on the left hand side of (16), and let $I\left(c_{0}, c_{1}, b_{-1,1}\right)$ correspond to the function on the left hand side of (17). Since the solution to this system of equations is unique, we can apply the Implicit Function Theorem. Implicit differentiation yields

$$
\frac{d c_{1}}{d b_{-1,1}}=\frac{-F_{c_{0}}^{0} I_{b_{-1,1}}+F_{b_{0}}^{0} I_{c_{0}}}{F_{c_{0}}^{0} I_{c_{1}}+\frac{F_{\mu_{0}}^{0} F_{c_{1}}^{1} I_{c_{0}}}{F_{\mu_{0}}^{1}}} .
$$

From the second order condition for (15) and (16), $F_{c_{0}}^{0}<0$ and $F_{c_{1}}^{1}<0$. Moreover, by inspection, $I_{c_{1}}<0$ and $F_{\mu_{0}}^{1}<0$. Finally, note that $F_{\mu_{0}}^{0} I_{c_{0}}=\left[I_{c_{0}}\right]^{2}>0$. This establishes that the denominator in $(B .3)$ is positive. To determine the sign of the numerator, let us expand the numerator by substituting in for the functions. By some algebra, the numerator is equal to

$\frac{1}{c_{0}}\left(-\frac{1}{c_{0}^{2}}-\eta(\gamma-1)\left(c_{0}+g\right)^{\gamma-2}\right)+\mu_{0}\left[-\frac{b_{-1,1}}{c_{0}^{4}}-\frac{1}{c_{0}} \eta \gamma(\gamma-1)\left(c_{0}+g\right)^{\gamma-2}-\frac{1}{c_{0}^{2}} \eta \gamma\left(c_{0}+g\right)^{\gamma-1}\right]<0$

This establishes that $c_{1}$ is strictly decreasing in $b_{-1,1}$.

Step 4. Given step 3, we complete the proof of the last part of the lemma by establishing that there exists $b_{-1,1}^{*} \in(0, \bar{b})$ for which the solution to $(15)-(17)$ admits $c_{1}=c^{\text {laffer }}$. We first establish that $b_{-1,1}^{*}$ exceeds 0 . Note that if $b_{-1,1}=0$ then the solution admits $c_{1}>c^{\text {laffer }}$. This is because $(15)-(17)$ imply that the solution admits 
$c_{0}=c_{1}$. Substitution into (17) yields

$$
\frac{c_{1}\left(1-\eta\left(c_{1}+g\right)^{\gamma}\right)}{1-\beta}=0
$$

This equation admits two solutions: $c_{1}=0$ and $c_{1}=\eta^{-1 / \gamma}-g$, and the optimal policy satisfies $c_{1}=\eta^{-1 / \gamma}-g$, since welfare is arbitrarily low otherwise. Given the definition of $c^{\text {laffer }}$ in (12) and the strict concavity of the objective in (12), it follows that $c^{\text {laffer must }}$ be between 0 and $\eta^{-1 / \gamma}-g$, which means that $c_{1}>c^{\text {laffer }}$.

Now let us consider the system of equations $(15)-(17)$ for $b_{-1,1}=b_{-1,1}^{*}$ and $c_{1}=c^{\text {laffer }}$. To see that this solution exists, note that $\frac{1}{c^{\text {laffer }}}-\eta\left(c^{\text {laffer }}+g\right)^{\gamma-1}>0$ since $c^{\text {laffer }}<c^{f b}$. Therefore, a value of $\mu_{0}>0$ which satisfies (16) exists. Multiply (15) by $c_{0}$ and substitute (17) into (15) to achieve

$1-\eta c_{0}\left(c_{0}+g\right)^{\gamma-1}+\mu_{0}\left(1-\eta\left(c_{0}(1+\gamma)+g\right)\left(c_{0}+g\right)^{\gamma-1}+\frac{\beta}{1-\beta}\left(1-\eta\left(c^{\text {laffer }}+g\right)^{\gamma}\right)\right)=0$.

Note that given the value of $\mu_{0}>0$ satisfying (16) for $c_{1}=c^{\text {laffer }}$, a solution to (B.5) which admits $c_{0}>0$ exists. This is because the left hand side of (B.5) goes to

$$
1+\mu_{0}\left(1-\eta g^{\gamma}+\frac{\beta}{1-\beta}\left(1-\eta\left(c^{\text {laffer }}+g\right)^{\gamma}\right)\right)>0
$$

as $c_{0}$ goes to 0 , where we have used the fact that $g<\left(\frac{1}{\eta}\right)^{1 / \gamma}$. As $c_{0}$ goes to infinity, the left hand side of (B.5) becomes arbitrarily negative. Therefore a solution to (B.5) for $c_{0}>0$ exists. Given that $b_{-1,1}$ enters linearly in (17), it follows that a value of $b_{-1,1}$ which satisfies the system also exists. This establishes the last part of the lemma.

\section{Proof of Proposition 1}

We consider each case separately.

Case 1. Suppose that $b_{-1,1}<b_{-1,1}^{*}$. From Lemma 2, the date 0 solution admits $c_{t}=c_{1}>c^{\text {laffer }} \forall t \geq 1$. To show that this solution is time-consistent, suppose that the date 0 government chooses $\left\{b_{0, k}\right\}_{k=1}^{\infty}$ satisfying

$$
b_{0, k}=c_{1}\left(1-\eta\left(c_{1}+g\right)^{\gamma}\right)>0 \forall k \geq 1
$$

for $c_{1}$ defined in $(15)-(17)$. The fact that $b_{0, k}>0$ follows from the fact that the highest value of $c_{1}>c^{\text {laffer }}$ is below that associated with $b_{-1,1}=0$ which satisfies (B.4). Now 
consider the solution to (18) - (19). Analogous arguments as those in steps 1 and 2 of the proof of Lemma 2 imply that the unique solution satisfies (19) and (20) for some $\mu_{1}>0$. Therefore, to check that the date 1 solution admits $c_{t}=c_{1} \forall t \geq 1$ for $c_{1}$ which satisfies (16), it is sufficient to check that there exists some $\mu_{1}>0$ satisfying (20). Using (B.6) to substitute in for $b_{0, k}$ in (20), we find that

$$
\mu_{1}=-\frac{1-\eta c_{1}\left(c_{1}+g\right)^{\gamma-1}}{1-\eta\left(c_{1}+g\right)^{\gamma}-\eta \gamma c_{1}\left(c_{1}+g\right)^{\gamma-1}}>0
$$

where we have appealed to the fact that $c_{1}<c^{f b}$ (from (16)) to assign a positive sign to the numerator in $(B .7)$ and the fact that $c_{1}>c^{\text {laffer }}$ to assign a negative sign to the denominator in (B.7). This establishes that the date 0 solution is time-consistent.

Case 2. Suppose by contradiction that the optimal date 0 policy is time-consistent. This would require (20) to hold for $c_{t}=c_{1} \forall t \geq 1$ for $c_{1}<c^{\text {laffer }}$ which satisfies (16). For a given $\mu_{1}$, satisfaction of (20) thus requires that $b_{0, k}=b_{0,1} \forall k \geq 1$. Equation (19) thus implies that $(B .6)$ for $b_{0, k}>0$ holds, and substitution of (B.6) into (20) implies that

$$
\mu_{1}=-\frac{1-\eta c_{1}\left(c_{1}+g\right)^{\gamma-1}}{1-\eta\left(c_{1}+g\right)^{\gamma}-\eta \gamma c_{1}\left(c_{1}+g\right)^{\gamma-1}}<0
$$

where we have appealed to the fact that $c_{1}<c^{f b}$ (from (16)) to assign a positive sign to the numerator and the fact that $c_{1}<c^{\text {laffer }}$ to assign a positive sign to the denominator. However, conditional on $\left\{b_{0, k}\right\}_{k=1}^{\infty}$ for $b_{0, k}=b_{0,1}>0 \forall k \geq 1$, the solution to (18) - (19) must admit a positive multiplier $\mu_{1}>0$, and this follows by analogous arguments as those in step 1 in the proof of Lemma 2, which contradicts (B.8). Therefore, the date 1 solution does not coincide with the date 0 solution.

\section{Appendix C. Proofs of Section 5}

\section{Proof of Lemma 3}

Note that if $b_{k}=b \forall k$, then from Assumption 1, the solution under commitment admits $\left\{c_{t}, n_{t}\right\}=\left\{c^{*}(b), n^{*}(b)\right\} \forall t$, and this solution can be implemented with $b_{k}^{\prime}=b$ given (32)(33). Since the MPCE satisfies the same constraints of the problem under commitment plus additional constraints regarding sequential optimality, it follows that

$$
W(\mathbf{B})=\frac{u\left(c^{*}(b), n^{*}(b)\right)}{1-\beta} \geq V(\mathbf{B})
$$


if $b_{k}=b \forall k$. Now consider optimal policy under the MPCE in (26) - (28) given $b_{k}=b \forall k$. A government has the option of choosing $c=c^{*}(b)$ and $n=n^{*}(b)$ together with $b_{k}^{\prime}=b$ $\forall k$. This satisfies the resource constraint (27) and the implementability constraint (28). Therefore, it follows that

$$
V(\mathbf{B}) \geq u\left(c^{*}(b), n^{*}(b)\right)+\beta V(\mathbf{B})
$$

Equations (C.9) and (C.10) imply that

$$
V(\mathbf{B})=W(\mathbf{B})
$$

By Assumption 1, $W(\mathbf{B})$ is uniquely characterized by $\left\{c_{k}, n_{k}\right\}=\left\{c^{*}(b), n^{*}(b)\right\} \forall k$. Therefore, it follows that any solution to $(26)-(28)$ given $b_{k}=b \forall k$ admits $c=c^{*}(b)$ and $n=n^{*}(b)$.

\section{Proof of Lemma 4}

Conditional on $\mathbf{B}$, if a solution admits $b_{k}^{\prime}=b_{k}$, then this means that $\mathbf{B}$ is an absorbing state with $\mathbf{B}=\mathbf{B}^{\prime}$ and consumption and labor are constant and equal to some $\{c, n\}$ from that period onward. Therefore, $h^{k}\left(\mathbf{B}^{\prime}\right)=\beta^{k} u_{c}(c, n) \forall k \geq 1$ for $h^{k}\left(\mathbf{B}^{\prime}\right)$ defined in (25). As such, (28) can be rewritten as

$$
u_{c}(c, n) c+u_{n}(c, n) n-u_{c}(c, n) b_{1}+u_{c}(c, n) \sum_{k=1}^{\infty} \beta^{k}\left(b_{k}^{\prime}-b_{k+1}\right)=0
$$

which combined with (35) and the fact that $b_{k}^{\prime}=b_{k}$ implies that

$$
u_{c}(c, n) c+u_{n}(c, n) n=u_{c}(c, n) \widehat{b}
$$

Now consider the solution to the following problem given $\widehat{b}$ :

$$
\max _{c, n} \frac{u(c, n)}{1-\beta} \text { s.t. } c+g=n \text { and }(C .13) \text {. }
$$

It is necessary that $V(\mathbf{B})$ be weakly below the value of $(C .14)$. This is because the solution to $V(\mathbf{B})$ also admits a constant consumption and labor (as in the program in $(C .14))$ and since the constraint set in (C.14) is slacker, since the program ignores the role of government debt in changing future policies. Note furthermore that the value of 
(C.14) equals $\left.W\left(\left\{b_{k}\right\}_{k=1}^{\infty}\right)\right|_{b_{k}=\widehat{b} \forall k}$, where this follows from Assumption 1. Therefore,

$$
V(\mathbf{B}) \leq\left. W\left(\left\{b_{k}\right\}_{k=1}^{\infty}\right)\right|_{b_{k}=\widehat{b} \forall k}
$$

Now consider the welfare of the government in the MPCE if, instead of choosing $b_{k}^{\prime}=b_{k}$ $\forall k$, it instead chooses $b_{k}^{\prime}=\widehat{b} \forall k$ with $c=c^{*}(\widehat{b})$ and $n=n^{*}(\widehat{b})$. It follows from Lemma 3 that under this perturbation, $h^{k}\left(\mathbf{B}^{\prime}\right)=\beta^{k} u_{c}\left(c^{*}(\widehat{b}), n^{*}(\widehat{b})\right) \forall k \geq 1$, which implies that the resource constraint (27) and implementability constraint (28) are satisfied under this deviation. Because the continuation value associated with this deviation is $\left.W\left(\left\{b_{k}\right\}_{k=1}^{\infty}\right)\right|_{b_{k}=\widehat{b} \forall k}$, it follows that for this deviation to be weakly dominated:

$$
\left.W\left(\left\{b_{k}\right\}_{k=1}^{\infty}\right)\right|_{b_{k}=\widehat{b} \forall k} \leq V(\mathbf{B})
$$

Given (C.15) and (C.16), it follows that $\left.W\left(\left\{b_{k}\right\}_{k=1}^{\infty}\right)\right|_{b_{k}=\widehat{b} \forall k}=V(\mathbf{B})$. Therefore, given B, there exists another solution to $(26)-(28)$ with $b_{k}^{\prime}=\widehat{b} \forall k$ which achieves the same welfare.

\section{Proof of Lemma 5}

Before proving this lemma, define $c^{\text {laffer }}$ analogously as in Section 3:

$$
c^{\text {laffer }}=\arg \max _{c}\left\{c+\frac{u_{n}(c, c+g)}{u_{c}(c, c+g)}(c+g)\right\}
$$

and let $b^{\text {laffer }}$ correspond to the value of the maximized objective in (C.17). It follows that a solution to $(29)-(31)$ exists if $b_{k}=b \forall k \geq 1$ if $b \leq b^{\text {laffer }}$.

Given this definition, we can proceed to prove this lemma by contradiction. By Lemma 4 ,

$$
V(\mathbf{B})=\left.W\left(\left\{b_{k}\right\}_{k=1}^{\infty}\right)\right|_{b_{k}=\widehat{b} \forall k}=\frac{u\left(c^{*}(\widehat{b}), n^{*}(\widehat{b})\right)}{1-\beta}
$$

for $\widehat{b}$ defined in (35). Now suppose that $b_{1} \neq \widehat{b}$. Given the definition of $\widehat{b}$, this means that $\widehat{b} \in(\underline{b}, \bar{b})$ and that $\widehat{b} \leq b^{\text {laffer }}$. We consider two cases separately.

Case 1. Suppose that $\widehat{b}<b^{\text {laffer }}$, and suppose that the government locally deviates to $b_{k}^{\prime}=\widetilde{b} \neq \widehat{b} \forall k$ so that from tomorrow onward, consumption is $c^{*}(\widetilde{b})$ and labor is $n^{*}(\widetilde{b})$, where this follows from Lemma 3 . This means that $h^{k}(\widetilde{\mathbf{B}})=\beta^{k} u_{c}\left(c^{*}(\widetilde{b}), n^{*}(\widetilde{b})\right)$ under the deviation. In order to satisfy the resource constraint and implementability condition, let 
the government deviate today to a consumption and labor allocation $\{\widetilde{c}, \widetilde{n}\}$ which satisfies

$$
\widetilde{c}+g=\widetilde{n}
$$

and

$$
\begin{gathered}
u_{c}(\widetilde{c}, \widetilde{n}) \widetilde{c}+u_{n}(\widetilde{c}, \widetilde{n}) \widetilde{n}-\left(u_{c}(\widetilde{c}, \widetilde{n})-u_{c}\left(c^{*}(\widetilde{b}), n^{*}(\widetilde{b})\right)\right) b_{1}= \\
u_{c}\left(c^{*}(\widetilde{b}), n^{*}(\widetilde{b})\right)\left(\widehat{b}+\frac{\beta}{1-\beta}(\widehat{b}-\widetilde{b})\right)
\end{gathered}
$$

where we have appealed to the definition of $\widehat{b}$ in (35). For such a deviation to be weakly dominated, it must be that

$$
V(\mathbf{B}) \geq u(\widetilde{c}, \widetilde{n})+\left.\beta W\left(\left\{b_{k}\right\}_{k=1}^{\infty}\right)\right|_{b_{k}=\widetilde{b} \forall k} .
$$

Clearly, the value of the right hand side of $(C .21)$ equals $V(\mathbf{B})$ if $\widetilde{b}=\widehat{b}$. Therefore, it must be that $\widetilde{b}=\widehat{b}$ with $\{\widetilde{c}, \widetilde{n}\}=\left\{c^{*}(\widehat{b}), n^{*}(\widehat{b})\right\}$ maximizes the right hand side of $(C .21)$ subject to (C.19), and (C.20). More specifically, we can consider the solution to the following program

$$
\max _{\widetilde{c} \widetilde{n}, \widetilde{b}} u(\widetilde{c}, \widetilde{n})+\left.\beta W\left(\left\{b_{k}\right\}_{k=1}^{\infty}\right)\right|_{b_{k}=\tilde{b} \forall k} \text { s.t. }(C .19) \text { and }(C .20) .
$$

For the deviation to not strictly increase welfare, $\widetilde{b}=\widehat{b}$ must be a solution to (C.22). By Assumption 1, $\left.W\left(\left\{b_{k}\right\}_{k=1}^{\infty}\right)\right|_{b_{k}=\tilde{b} \forall k}=u\left(c^{*}, n^{*}\right) /(1-\beta)$ where $\left\{c^{*}, n^{*}\right\}=\left\{c^{*}(\widetilde{b}), n^{*}(\widetilde{b})\right\}$ are the unique levels of consumption and labor which maximize welfare given $\widetilde{b}$ and are defined in (32) and (33). Letting $\mu_{1}$ represent the Lagrange multiplier on the implementability condition for the program defining $\left.W\left(\left\{b_{k}\right\}_{k=1}^{\infty}\right)\right|_{b_{k}=\tilde{b} \forall k}$ in (29) - (31), it follows from first order conditions that

$$
\begin{gathered}
u_{c}\left(c^{*}, n^{*}\right)+u_{n}\left(c^{*}, n^{*}\right)+ \\
u_{c}\left(c^{*}, n^{*}\right)+u_{n}\left(c^{*}, n^{*}\right) \\
\mu_{1}\left(\begin{array}{c}
u_{c c}\left(c^{*}, b^{*}\right)\left(c^{*}-\widetilde{b}\right)+u_{c n}\left(c^{*}, n^{*}\right)\left(c^{*}-\widetilde{b}+n^{*}\right)+u_{n n}\left(c^{*}, n^{*}\right) n^{*}
\end{array}\right)=0 .
\end{gathered}
$$

Since $\left\{c^{*}, n^{*}\right\} \neq\left\{c^{f b}, n^{f b}\right\}$ by the statement of the lemma, (C.23) implies that $\mu_{1} \neq 0$. Using this observation, implicit differentiation of (32) and (33) taking (C.23) into account implies

$$
c^{* \prime}(\widetilde{b})=n^{* \prime}(\widetilde{b})=-\mu_{1} \frac{u_{c}\left(c^{*}, n^{*}\right)}{u_{c}\left(c^{*}, n^{*}\right)+u_{n}\left(c^{*}, n^{*}\right)} .
$$


Finally, by the Envelope condition,

$$
\frac{\left.d W\left(\left\{b_{k}\right\}_{k=1}^{\infty}\right)\right|_{b_{k}=\widetilde{b} \forall k}}{\widetilde{d b}}=-\mu_{1} \frac{u_{c}\left(c^{*}, n^{*}\right)}{1-\beta} .
$$

Now consider the solution to $(C .22)$. Let $\mu_{0}$ correspond to the Lagrange multiplier on $(C .20)$. First order conditions with respect to $\widetilde{c}$ and $\widetilde{n}$ imply

$$
\left.\begin{array}{c}
u_{c}(\widetilde{c}, \widetilde{n})+u_{n}(\widetilde{c}, \widetilde{n})+ \\
u_{c}(\widetilde{c}, \widetilde{n})+u_{n}(\widetilde{c}, \widetilde{n}) \\
+u_{c c}(\widetilde{c}, \widetilde{n})\left(\widetilde{c}-b_{1}\right)+u_{c n}(\widetilde{c}, \widetilde{n})\left(\widetilde{c}-b_{1}+\widetilde{n}\right)+u_{n n}(\widetilde{c}, \widetilde{n}) \widetilde{n}
\end{array}\right)=0 .
$$

Since $\{\widetilde{c}, \widetilde{n}\} \neq\left\{c^{f b}, n^{f b}\right\}$ by the statement of the lemma, (C.26) implies that $\mu_{0} \neq 0$. Since the solution admits $\widetilde{b}=\widehat{b} \in(\underline{b}, \bar{b})$, then we can ignore the bounds on government debt, and first order conditions with respect to $\widetilde{b}$ taking into account (C.24) and (C.25) yields

$$
\mu_{0} \mu_{1} \frac{u_{c c}\left(c^{*}, n^{*}\right)+u_{c n}\left(c^{*}, n^{*}\right)}{u_{c}\left(c^{*}, n^{*}\right)+u_{n}\left(c^{*}, n^{*}\right)}\left(\widehat{b}-b_{1}+\frac{\beta}{1-\beta}(\widehat{b}-\widetilde{b})\right)+\frac{\beta}{1-\beta}\left(\mu_{0}-\mu_{1}\right)=0 .
$$

Note that $(C .23)$ and (C.26) imply that

$$
\frac{\beta}{1-\beta}\left(\mu_{0}-\mu_{1}\right)=\frac{\beta}{1-\beta} \mu_{0} \mu_{1} \frac{u_{c c}\left(c^{*}, n^{*}\right)+u_{c n}\left(c^{*}, n^{*}\right)}{u_{c}\left(c^{*}, n^{*}\right)+u_{n}\left(c^{*}, n^{*}\right)}\left(\vec{b}-b_{1}\right)
$$

Now consider if $\widetilde{b}=\widehat{b}$ so that $\{\widetilde{c}, \widetilde{n}\}=\left\{c^{*}, n^{*}\right\}$. In that case, use (C.28) to substitute into (C.27) to achieve:

$$
\left.\mu_{0} \mu_{1} \frac{u_{c c}\left(c^{*}, n^{*}\right)+u_{c n}\left(c^{*}, n^{*}\right)}{u_{c}\left(c^{*}, n^{*}\right)+u_{n}\left(c^{*}, n^{*}\right)} \widehat{(b}-b_{1}\right)=0
$$

If it were the case that $\widehat{b} \neq b_{1}$, then $(C .29)$ would require that $u_{c c}\left(c^{*}, n^{*}\right)+u_{c n}\left(c^{*}, n^{*}\right)=0$, which contradicts the fact that $u_{c c}\left(c^{*}, n^{*}\right)+u_{c n}\left(c^{*}, n^{*}\right)<0$. Therefore, $\widehat{b}=b_{1}$.

Case 2. Suppose that $\widehat{b}=b^{\text {laffer }}$. In this case, consider an analogous perturbation as in case 1 which reduces $\widehat{b}$ locally. For such a perturbation to be weakly dominated, the analog of $(C .29)$ requires

$$
\mu_{0} \mu_{1} \frac{u_{c c}\left(c^{*}, n^{*}\right)+u_{c n}\left(c^{*}, n^{*}\right)}{u_{c}\left(c^{*}, n^{*}\right)+u_{n}\left(c^{*}, n^{*}\right)}\left(\widehat{b}-b_{1}\right) \geq 0
$$

It follows from $(C .25)$ that $\mu_{1}>0$ since any reduction in inherited debt can facilitate 
higher consumption and higher welfare. Since $u_{c c}\left(c^{*}, n^{*}\right)+u_{c n}\left(c^{*}, n^{*}\right)<0$, satisfaction of (C.30) requires

$$
\mu_{0}\left(\widehat{b}-b_{1}\right) \leq 0
$$

Given that $\{\widetilde{c}, \widetilde{n}\}=\left\{c^{*}, n^{*}\right\}=\left\{c^{\text {laffer }}, c^{\text {laffer }}+g\right\}$, it can be verified from $(C .17)$ that if $b_{1}<(>) \widehat{b}=b^{\text {laffer }}$, then $(C .26)$ implies that $\mu_{0}>(<) 0$. This follows from the fact that $c^{\text {laffer }}<c^{f b}$ and the term in parentheses multiplying $\mu_{0}$ in equation (C.26) is equal to 0 if $b_{1}=b^{\text {laffer }}$ and is increasing in $b_{1}$. Therefore, (C.31) cannot hold unless $\widehat{b}=b_{1}$.

\section{Proof of Lemma 6}

Suppose that $b_{l}=\widehat{b} \forall l \leq m$. Given $\mathbf{B}$, let $\widehat{\mathbf{B}}(1)$ represent the portfolio which sets $\widehat{b}_{k}=b_{k+1}$ so that no retrading takes place. Note that in such a portfolio, $\widehat{b}_{1}=b_{2}$. Define $\widehat{\mathbf{B}}(2)$ analogously as the portfolio involving no retrading at the next date, so that $\widehat{b}_{k}=b_{k+2}$ under $\widehat{\mathbf{B}}(2)$, and define $\widehat{\mathbf{B}}(l) \forall l \leq m$ analogously. In any MPCE for which $b_{1}=\widehat{b}$, a possible deviation sets $\{c, n\}=\left\{c^{*}(\widehat{b}), n^{*}(\widehat{b})\right\}$ and $b_{k}^{\prime}=b_{k+1}$ so that no retrading takes place, where this deviation satisfies the resource constraint and implementability condition given $(32)-(33)$. For such a deviation to be weakly dominated, it is necessary that:

$$
V(\mathbf{B}) \geq u\left(c^{*}(\widehat{b}), n^{*}(\widehat{b})\right)+\beta V(\widehat{\mathbf{B}}(1)) .
$$

Forward induction on this argument implies that

$$
V(\mathbf{B}) \geq \sum_{l=0}^{m-1} \beta^{l} u\left(c^{*}(\widehat{b}), n^{*}(\widehat{b})\right)+\beta^{m} V(\widehat{\mathbf{B}}(m))
$$

Combining (C.18) with $(C .33)$, we achieve

$$
V(\mathbf{B}) \geq V(\widehat{\mathbf{B}}(m))
$$

Now consider optimal policy starting from $\widehat{\mathbf{B}}(m)$. Note that since $b_{l}=\widehat{b} \forall l \leq m$, then following the same arguments as in the proof of Lemma 4, a feasible strategy starting from $\widehat{\mathbf{B}}(m)$ is to issue a flat debt maturity with all bonds equal to $\widehat{b}$. Such a strategy ensures a constant consumption and labor allocation forever equal to $\left\{c^{*}(\widehat{b}), n^{*}(\widehat{b})\right\}$. As such, it follows that $(C .34)$ holds with equality and that choosing a flat maturity distribution going forward is optimal.

Now we prove by contradiction that $b_{m+1}=\widehat{b}$. Suppose it were the case that $b_{m+1} \neq \widehat{b}$. This means that starting from $\widehat{\mathbf{B}}(m)$, the immediate debt which is owed by the government 
does not equal $\widehat{b}$. If this is the case, then the same arguments as those in the proof of Lemma 5 imply that there exists a deviation from the government's equilibrium strategy at $\widehat{\mathbf{B}}(m)$ which can strictly increase the government's welfare. However, if this is the case, (C.34) which holds with equality is violated. Therefore, it must be that $b_{m+1}=\widehat{b}$.

\section{Proof of Proposition 2 and Corollaries 1 and 2}

The proof of Proposition 2 follows directly by induction after appealing to Lemmas 5 and 6.

To prove the first corollary, note that for the statement of Proposition 2 to be false, it is necessary that $\{c, n\}=\left\{c^{f b}, n^{f b}\right\}$. However, if this is the case, then (C.12) implies that

$$
c^{f b}+\frac{u_{n}\left(c^{f b}, n^{f b}\right)}{u_{c}\left(c^{f b}, n^{f b}\right)} n^{f b}=-g=\sum_{k=1}^{\infty} \beta^{k-1}(1-\beta) b_{k} \geq \underline{b}
$$

which contradicts $b_{k}>-g$.

To prove the second corollary, note that from Lemma 3, it is necessary that the continuation equilibrium starting from a flat government debt maturity entail consumption and labor equal to $\left\{c^{*}(b), n^{*}(b)\right\}$ forever. The arguments in the proof of Lemmas 5 and 6 imply that if the government were to choose a non-flat maturity distribution going forward, future governments would not choose $\left\{c^{*}(b), n^{*}(b)\right\}$ forever. Therefore, all solutions to $(26)-(28)$ admit $b_{k}^{\prime}=b \forall k$.

\section{Appendix D. Finite Horizon Analysis}

In this section, we explore the transition path of debt maturity in a finite horizon. We consider a three-period quasilinear economy that we analytically characterize using backward induction. The initial debt maturity distribution is declining in the horizon and maturities beyond a certain horizon are equal. The proofs for the results of this section are in the Online Appendix.

Suppose that preferences satisfy (11) and are quasilinear with $\gamma=1$. The horizon is finite with $t=0,1,2$. We impose bounds on government debt where $b_{t-1, k} \in\left[-g, c^{f b}\right]$ $\forall t, k$ for $c^{f b}=1 / \eta$ given by the preference structure. ${ }^{9}$ In this setup, $c^{\text {laffer }}$ defined in (12)

\footnotetext{
${ }^{9}$ These debt limits are non-binding along the equilibrium path, but they allow us to characterize continuation equilibria off the equilibrium path.
} 
satisfies

$$
c^{\text {laffer }}=\frac{1-\eta g}{2 \eta} .
$$

We consider an economy in which $b_{-1,1} \geq b_{-1,2}=b_{-1,3} \geq 0$. Thus, the initial debt maturity distribution is declining in the horizon and maturities from date 1 onward are equal. We observe that in this environment, the solution under commitment admits $c_{1}=$ $c_{2}$, and this follows by analogous logic as in the example of Section 3. Furthermore, using the same arguments from that section, we can construct examples in which initial debt $\left\{b_{-1,1}, b_{-1,2}, b_{-1,3}\right\}$ with elements within $\left[-g, c^{f b}\right]$ implies a solution under commitment with $c_{1}=c_{2}<c^{\text {laffer }}{ }^{10}$

We characterize the path of consumption and debt using backward induction. At date 2 , the government inherits debt $b_{1,1}$ and chooses a value of consumption that satisfies the implementability condition:

$$
c_{2}\left(1-\eta\left(c_{2}+g\right)\right)=b_{1,1} .
$$

Conditional on $b_{1,1}$, the value of consumption $c_{2}$ satisfying $(D .37)$ is unique since $c_{2} \geq$ $c^{\text {laffer }}$, where this follows by analogous logic as in Section 3. A government lacking commitment at date 2 would never choose a tax rate on the downward sloping portion of the Laffer curve; a tax rate on the upward sloping portion associated with $c_{2} \in\left(c^{l a f f e r}, c^{f b}\right)$ raises the same revenue and makes the government strictly better off.

Taking this into account, the government at date 1 maximizes welfare by solving the following problem, where we have substituted in for labor $n_{t}$ using the resource constraint (1):

$$
\begin{gathered}
\max _{c_{1}, c_{2}, b_{1,1}} \sum_{t=1,2} \beta^{t-1}\left(\log c_{t}-\eta c_{t}\right) \\
\text { s.t. } \\
\sum_{t=1,2} \beta^{t-1}\left(1-\eta\left(c_{t}+g\right)-\frac{b_{0, t}}{c_{t}}\right)=0, \\
c_{2}\left(1-\eta\left(c_{2}+g\right)\right)=b_{1,1}, \\
b_{1,1} \in\left[-g, c^{f b}\right], \text { and } \\
c_{2} \geq c^{l a f f e r} .
\end{gathered}
$$

Note that analogous arguments to those of Section 3 imply that $(D .39)$ can be written in relaxed form as a weak inequality constraint. The next lemma characterizes the solution

\footnotetext{
${ }^{10}$ For example, if $b_{-1,1}=c^{f b}>b_{-1,2}=b_{-1,3}=0$, we can show that $c_{1}=c_{2}<c^{\text {laffer }}$ if the discount factor $\beta$ is sufficiently low.
} 
to this problem by providing conditions on $c_{1}$ and $c_{2}$ which must hold given any inherited debt $\left\{b_{0,1}, b_{0,2}\right\}$ at date 1 .

Lemma 7 For any $\left\{b_{0,1}, b_{0,2}\right\}$, the solution to (D.38)-(D.42) satisfies the following weak inequality constraints:

$$
\begin{aligned}
& c_{1}+\beta c_{2} \geq c^{\text {laffer }}+\beta c^{\text {laffer }}, \text { and } \\
& c_{2} \geq c^{\text {laffer }} .
\end{aligned}
$$

This lemma provides necessary, but not sufficient, conditions to characterize the solution to $(D .38)-(D .42)$. These conditions put a lower bound on the discounted sum of consumption from date 1 onward. (D.44) is clearly implied by (D.42) and stems from the lack of commitment at date 2 .

Satisfaction of (D.43) stems from the lack of commitment at date 1. More specifically, (D.43) implies that it is not possible for $c_{1}<c^{\text {laffer }}$ and $c_{2}<c^{\text {laffer }}$; all future tax rates cannot be on the downward sloping portion of the Laffer curve. This is true even in the relaxed version of $(D .38)-(D .42)$ which ignores $(D .42)$. If it were the case that $c_{1}<c^{\text {laffer }}$ and $c_{2}<c^{\text {laffer }}$, then a deviation to $c_{1}>c^{\text {laffer }}$ or $c_{2}>c^{\text {laffer }}$ which raises the same revenue continues to satisfy the (relaxed) implementability condition (D.39) and strictly increases welfare. ${ }^{11}$ In addition, note that (D.43) does not impose a clear lower bound on $c_{1}$; a solution to $(D .38)-(D .42)$ could in principle admit $c_{1}<c^{\text {laffer }}$, however this would require $c_{2}>c^{\text {laffer }}$. Intuitively, a government at date 1 could choose a tax rate on the downward sloping portion of the Laffer curve at date 1 in order to increase short-term interest rates and buy back its outstanding long-term debt $b_{0,2}$ at a lower price, which would allow for a higher value of $c_{2}$.

Now consider the problem of the government at date 0 . Using Lemma 7, we can

\footnotetext{
${ }^{11}$ More specifically, if the primary surplus at date 1 is below $b_{0,1}$, then a deviation to $c_{1}>c^{\text {laffer }}$ relaxes (D.39) by reducing the short-term interest rate. If the primary surplus at date 1 exceeds $b_{0,1}$, then a deviation to $c_{2}>c^{\text {laffer }}$ relaxes $(D .39)$ by increasing the short-term interest rate.
} 
consider the relaxed problem of the government at date 0 :

$$
\begin{gathered}
\max _{c_{0}, c_{1}, c_{2}} \sum_{t=0,1,2} \beta^{t}\left(\log c_{t}-\eta c_{t}\right) \\
\text { s.t. } \\
\sum_{t=0,1,2} \beta^{t}\left(1-\eta\left(c_{t}+g\right)-\frac{b_{-1, t+1}}{c_{t}}\right)=0, \\
c_{1}+\beta c_{2} \geq c^{\text {laffer }}+\beta c^{\text {laffer }}, \text { and } \\
c_{2} \geq c^{\text {laffer }} .
\end{gathered}
$$

This program corresponds to the date 0 program under commitment subject to additional constraints $(D .47)$ and (D.48). Recall that the program under commitment admits a solution with $c_{1}=c_{2}$. Note that this program which adds constraints $(D .47)$ and (D.48) ignores the bounds on the date 0 government's debt issuance and only considers necessary, as opposed to sufficient, conditions for the values of $c_{1}$ and $c_{2}$ to be chosen by future governments. As such, welfare in the MPCE must be weakly below the solution to $(D .45)-(D .48)$. In the Online Appendix, we characterize the solution to $(D .45)-(D .48)$, and we verify that this solution corresponds to the unique MPCE in the three-period economy. This leads to the following main result of this section.

Proposition 3 (MPCE in finite horizon) The unique MPCE admits a sequence $\left\{c_{0}, c_{1}, c_{2}\right\}$ that satisfies $(D .45)-(D .48)$ and admits $b_{0,1}=b_{0,2}$. If the solution under commitment admits $c_{1}=c_{2}<c^{\text {laffer }}$, then the MPCE and commitment solution do not coincide, and the MPCE admits

$$
b_{0,1}=b_{0,2}=c^{\text {laffer }}\left(1-\eta\left(c^{\text {laffer }}+g\right)\right)
$$

This proposition states that the unique MPCE is characterized by the constrained date 0 problem $(D .45)-(D .48)$ and admits a flat maturity distribution $b_{0,1}=b_{0,2}$, where these values of debt correspond to the natural debt limit characterized by (D.49) if the solution under commitment admits $c_{1}=c_{2}<c^{\text {laffer }}$.

In the case where the solution under commitment admits $c_{1}=c_{2}>c^{\text {laffer }}-$ so that (D.47) and (D.48) do not bind - this result is immediate and follows from the arguments in Lucas-Stokey. Optimal tax rates under commitment mirror initial maturities, and are therefore stationary beyond a particular horizon. This eventual stability is guaranteed with a transition to a flat maturity under no commitment, since otherwise the date 1 government would not choose $c_{1}=c_{2}$. 
In the cases where the commitment and no-commitment solutions do not coincide, the argument is more subtle. The date 0 government clearly desires a stable tax rate from date 1 onward given its initial maturities. However, if this desired tax rate exceeds the revenue-maximizing tax rate defining the peak of the Laffer curve, the date 0 government realizes that it cannot commit the date 1 and date 2 governments to its desired policy. Facing this binding upper bound on future tax rates captured by (D.47) and (D.48), the government chooses all future tax rates to equal the revenue-maximizing tax rate. To achieve this future outcome, it issues a flat maturity distribution associated with the natural debt limit.

This example suggests that our results from the main text are robust to the consideration of a finite horizon economy. We have also verified through numerical examples that Proposition 3 continues to hold with preferences that admit $\gamma>1$ in a horizon that exceeds three periods. Details available upon request. 


\section{OnLine APPENDiX}

\section{Online Appendix E. Proofs of Appendix D.}

\section{Proof of Lemma 7}

$(D .44)$ is implied by $(D .42)$. Let us consider a relaxed representation of $(D .38)-(D .42)$ in which we ignore $(D .41)$ and we replace $(D .39)$ with a weak inequality constraint:

$$
\sum_{t=1,2} \beta^{t-1}\left(1-\eta\left(c_{t}+g\right)-\frac{b_{0, t}}{c_{t}}\right) \geq 0 .
$$

We establish that the solution to the relaxed problem satisfies $(D .43)$ and we verify that (D.39) and (D.41) are satisfied under this solution.

Step 1. Analogous arguments as in step 1 of Lemma 2 imply that since $b_{0,1} \geq-g$ and $b_{0,2} \geq-g$, (E.50) holds as an equality in the relaxed problem. Note furthermore that if $b_{0,1} \geq 0$ and $b_{0,2} \geq 0$, the constraint set is convex so that the solution is unique.

Step 2. The choice of $c_{1}$ is characterized by the following first order condition for $\mu_{1} \geq 0$ which represents the Lagrange multiplier on (E.50):

$$
\frac{1}{c_{1}}-\eta=\mu_{1}\left(\eta-\frac{b_{0,1}}{c_{1}^{2}}\right)
$$

We can show that

$$
\eta-\frac{b_{0,1}}{c_{1}^{2}} \geq 0 .
$$

Suppose that $(E .52)$ does not hold. In that case, $b_{0,1}>0>-g$, which means that (E.50) is a binding constraint with $\mu_{1}>0$, implying that the right hand side of $(E .51)$ is negative. For the left hand side of $(E .51)$ to be negative, this requires that $c_{1}>c^{f b}$. Substituting this fact back into the right hand side of $(E .51)$, this means that

$$
b_{0,1}>\eta c_{1}^{2}>c^{f b}
$$

which is a contradiction since $b_{0,1} \leq c^{f b}$. Therefore, (E.52) is necessary.

Step 3. The choice of $c_{2}$ is characterized by the following first order condition for 
$\kappa \geq 0$ which represents the Lagrange multiplier on $(D .42)$ :

$$
\frac{1}{c_{2}}-\eta+\kappa=\mu_{1}\left(\eta-\frac{b_{0,2}}{c_{2}^{2}}\right) .
$$

Analogous arguments using this condition as in step 2 imply that

$$
\eta-\frac{b_{0,2}}{c_{2}^{2}} \geq 0 .
$$

Combination of (E.52) and (E.54) taking into account the definition of $c^{\text {laffer }}$ in (D.36) and (E.50) which binds and implies (D.43).

Step 4. We are left to check that (D.41) is satisfied. There are two cases to consider.

Case 1. Suppose that $(D .42)$ holds as an equality in the solution to the relaxed problem. In that case, $c_{2}=c^{\text {laffer }}$ and $(D .40)$ implies that

$$
b_{1,1}=c^{\text {laffer }}\left(1-\eta\left(c^{\text {laffer }}+g\right)\right) \in\left(-g, c^{f b}\right)
$$

so that $(D .41)$ is satisfied.

Case 2. Suppose that $(D .42)$ holds as a strict inequality in the solution to the relaxed problem. In this case, the solution is characterized by (E.51) and (E.53) for $\kappa=0$. Given $(E .52)$ and (E.54), it follows that (E.51) and (E.53) can only be satisfied for $c_{1} \leq c^{f b}$ and $c_{2} \leq c^{f b}$. Since $c_{2}>c^{\text {laffer }},(D .40)$ implies that

$$
b_{1,1}<c^{\text {laffer }}\left(1-\eta\left(c^{\text {laffer }}+g\right)\right)<c^{f b} .
$$

To check that $b_{1,1} \geq-g$, suppose it were the case that the solution to the relaxed problem admitted $b_{1,1}<-g$. In this case, satisfaction of $(D .40)$ would require that $c_{2}>c^{f b}$ which contradicts the fact that $c_{2}<c^{f b}$. Therefore, $(D .41)$ is satisfied.

\section{Proof of Proposition 3}

We proceed by characterizing the solution to the relaxed problem in $(D .45)-(D .48)$. We then complete the proof by showing that the solution to this problem is the unique MPCE which admits $b_{0,1}=b_{0,2}$.

Step 1. Let us consider the relaxed version of $(D .45)-(D .48)$ which ignores $(D .48)$ 
and which replaces $(D .46)$ with a relaxed constraint

$$
\sum_{t=0,1,2} \beta^{t}\left(1-\eta\left(c_{t}+g\right)-\frac{b_{-1, t+1}}{c_{t}}\right) \geq 0 .
$$

Analogous arguments as in step 1 of Lemma 2 imply that since $b_{-1, t} \geq 0 \forall t,(E .55)$ is a binding constraint in the relaxed problem and admits a positive Lagrange multiplier $\mu_{0}>0$. Let us consider the solution to this relaxed problem and then verify that constraint (D.48) is satisfied.

Step 2. Analogous arguments as in step 2 of Lemma 2 imply that since $b_{-1, t} \geq 0$, the constraint set in the relaxed problem is convex, which means that first order conditions with respect to $c_{t}$ are necessary and sufficient to characterize the unique optimum. Letting $\beta \phi$ correspond to the Lagrange multiplier on constraint (D.47), first order conditions are:

$$
\begin{aligned}
\frac{1}{c_{0}}-\eta & =\mu_{0}\left(\eta-\frac{b_{-1,1}}{c_{0}^{2}}\right), \text { and } \\
\frac{1}{c_{t}}-\eta+\phi & =\mu_{0}\left(\eta-\frac{b_{-1, t+1}}{c_{0}^{2}}\right) \text { for } t=1,2 .
\end{aligned}
$$

$(E .56)-(E .57)$ imply that since $b_{-1,2}=b_{-1,3}$, the solution admits $c_{1}=c_{2}$. This means that (D.48) is satisfied, since if $\phi>0$, then $c_{1}=c_{2}=c^{\text {laffer }}$, otherwise $c_{1}=c_{2} \geq c^{\text {laffer }}$. Note furthermore that since $\mu_{0}>0, c_{t}<c^{f b}$ with

$$
\eta-\frac{b_{-1, t+1}}{c_{t}^{2}} \geq 0
$$

for $t=0,1,2$ where this follows from the fact that $b_{-1, t} \leq c^{f b}$ using analogous arguments as in step 2 in the proof of Lemma 7.

Step 3. By Lemma 7, an MPCE cannot achieve higher welfare than the solution to $(D .45)-(D .48)$. We now establish that the solution to $(D .45)-(D .48)$ is supported by an MPCE with $b_{0,1}=b_{0,2} \in\left[0, c^{f b}\right]$. Suppose that the date 0 government selects $b_{0,1}=b_{0,2}$ which satisfy

$$
b_{0,1}=c_{1}\left(1-\eta\left(c_{1}+g\right)\right)
$$

where $c_{1}$ corresponds to the values of consumption satisfying (E.57). Let us assume and later verify that this choice of debt satisfies

$$
b_{0,1} \in\left[0, c^{\text {laffer }}\left(1-\eta\left(c^{\text {laffer }}+g\right)\right)\right]
$$


so that it is feasible ( since $\left.c^{\text {laffer }}\left(1-\eta\left(c^{\text {laffer }}+g\right)\right)<c^{f b}\right)$. Consider the continuation equilibrium from date 1 onward characterized by the solution to $(D .38)-(D .42)$ and analyzed in the proof of Lemma 7. By step 1 in the proof of that lemma, if $b_{0,1}=b_{0,2} \geq 0$, the solution is unique and characterized by the date 1 implementability condition $(D .39)$ and the date 1 first order conditions $(E .51)$ and (E.53) for some positive $\mu_{1} \cdot c_{1}=c_{2}$ satisfying (E.57) clearly satisfy (D.39). To check that (E.51) and (E.53) are satisfied for positive $\mu_{1}$ under these values, set $\kappa=0$ (so that $c_{1}=c_{2}$ from (E.51) and (E.53)), and let us verify that the implied $\mu_{1}$ is positive. Substituting (E.59) into (E.51), we achieve

$$
\mu_{1}=-\frac{1-\eta c_{1}}{1-\eta\left(c_{1}+g\right)-\eta c_{1}}>0
$$

where we have appealed to the fact that $c_{1} \in\left[c^{\text {laffer }}, c^{f b}\right)$. Therefore, the date 1 government selects the same allocation as the date 0 government. We now verify that $(E .60)$ holds. There are two cases to consider.

Case 1. Suppose that the date 0 solution admits $c_{1}=c_{2}=c^{\text {laffer }}$. In that case $b_{0,1}=b_{0,2}=c^{\text {laffer }}\left(1-\eta\left(c^{\text {laffer }}+g\right)\right)$ so that debt issuance is feasible.

Case 2. Suppose that the date 0 solution admits $c_{1}=c_{2}>c^{\text {laffer }}$. Since the right hand side of $(E .59)$ is strictly below $c^{\text {laffer }}\left(1-\eta\left(c^{\text {laffer }}+g\right)\right)<c^{f b}$, it follows that $b_{0,1}=b_{0,2}<c^{f b}$. To verify that $b_{0,1}=b_{0,2} \geq 0$, note that $(D .46)$ given $c_{1}=c_{2}$ and $b_{-1,2}=b_{-1,3}$ can be rewritten as

$$
1-\eta\left(c_{0}+g\right)-\frac{b_{-1,1}}{c_{0}}+\beta(1+\beta)\left(1-\eta\left(c_{1}+g\right)-\frac{b_{-1,2}}{c_{1}}\right)=0
$$

From (E.58), the left hand side of $(E .61)$ is decreasing in $c_{0}$ and $c_{1}$. Following similar arguments to step 2 in the proof of Lemma 2, equations $(E .56)-(E .57)$, imply that $c_{0} \geq c_{1}=c_{2}$ since $b_{-1,1} \geq b_{-1,2}=b_{-1,3} \geq 0$. Substituting these inequalities into (E.61), which is declining in $c_{0}$ and $c_{1}$, yields

$$
1-\eta\left(c_{1}+g\right) \geq 0
$$

Therefore, $b_{0,1}$ satisfying (E.59) is weakly positive. Therefore, the solution to $(D .45)-$ (D.48) represents an MPCE in which the date 0 government issues a flat maturity with $b_{0,1}=b_{0,2}$.

Step 4. We complete the proof by showing that there does not exist an MPCE which does not achieve the same welfare as $(D .45)-(D .48)$ and that $b_{0,1}=b_{0,2}$ is necessary in the MPCE. If there existed an MPCE which did not provide welfare characterized by 
$(D .45)-(D .48)$, then the MPCE would provide strictly lower welfare than the solution to $(D .45)-(D .48)$, where this follows from Lemma 7 . However, in this situation, the government at date 0 could deviate to choose $b_{0,1}=b_{0,2}$ which satisfy (E.59) for $c_{1}=c_{2}$ which correspond to the values of consumption satisfying (E.57). By step 3, this choice would lead the date 0 government to achieve the same welfare as $(D .45)-(D .48)$ and make it strictly better off. Therefore, any MPCE coincides with the solution to $(D .45)-(D .48)$. We complete this step then by proving that $b_{0,1}=b_{0,2}$ is necessary to induce the date 1 government to pursue the same policy which satisfies $(D .45)-(D .48)$. There are two cases to consider analogous to the cases considered in step 3.

Case 1. Suppose that the date 0 solution admits $c_{1}=c_{2}=c^{\text {laffer }}$. Suppose by contradiction that some value $b_{0,1} \neq b_{0,2}$ could induce the date 1 government solving $(D .38)-(D .42)$ to choose $c_{1}=c_{2}=c^{\text {laffer }}$, where satisfaction of $(D .39)$ requires

$$
b_{0,1}+\beta b_{0,2}=(1+\beta) c^{\text {laffer }}\left(1-\eta\left(c^{\text {laffer }}+g\right)\right) .
$$

For (E.51) and (E.53) to be satisfied, this would require $\kappa>0$, since otherwise (E.51) and (E.53) would imply $c_{1} \neq c_{2}$ since $b_{0,1} \neq b_{0,2}$ in the date 1 problem. Analogous arguments as in step 2 and 3 of the proof of Lemma 7 imply that (E.52) and (E.54) must hold. However, note that

$$
\eta-\frac{b_{0, t}}{c_{t}^{2}}=0
$$

if $c_{t}=c^{\text {laffer }}$ and $b_{0, t}=c^{\text {laffer }}\left(1-\eta\left(c^{\text {laffer }}+g\right)\right)$, where we have appealed to the definition of $c^{\text {laffer }}$ in (D.36). Since (E.63) implies that either $b_{0,1}>c^{\text {laffer }}\left(1-\eta\left(c^{\text {laffer }}+g\right)\right)$ or $b_{0,2}>c^{\text {laffer }}\left(1-\eta\left(c^{\text {laffer }}+g\right)\right)$ and since the left hand side of $(E .64)$ is strictly decreasing in $b_{0, t}$, it follows that (E.52) and (E.54) cannot simultaneously hold, which is a contradiction. Therefore, $b_{0,1}=b_{0,2}$ uniquely guarantee that $c_{1}=c_{2}$ in this case.

Case 2. Suppose that the date 0 solution admits $c_{1}=c_{2}>c^{\text {laffer }}$. Suppose by contradiction that some value $b_{0,1} \neq b_{0,2}$ could induce the date 1 government solving $(D .38)-(D .42)$ to choose $c_{1}=c_{2}>c^{\text {laffer }}$. In this case, $(E .51)$ and $(E .53)$ would need to be satisfied with $\kappa=0$. However, this is not possible since $b_{0,1} \neq b_{0,2}$ implies $c_{1} \neq c_{2}$. 